Document downloaded from:

http://hdl.handle.net/10251/65966

This paper must be cited as:

Desantes Fernández, JM.; Salvador Rubio, FJ.; Carreres Talens, M.; Martínez López, J. (2015). Large-eddy simulation analysis of the influence of the needle lift on the cavitation in diesel injector nozzles. Proceedings of the Institution of Mechanical Engineers, Part D: Journal of Automobile Engineering. 229(4):407-423. doi:10.1177/0954407014542627.

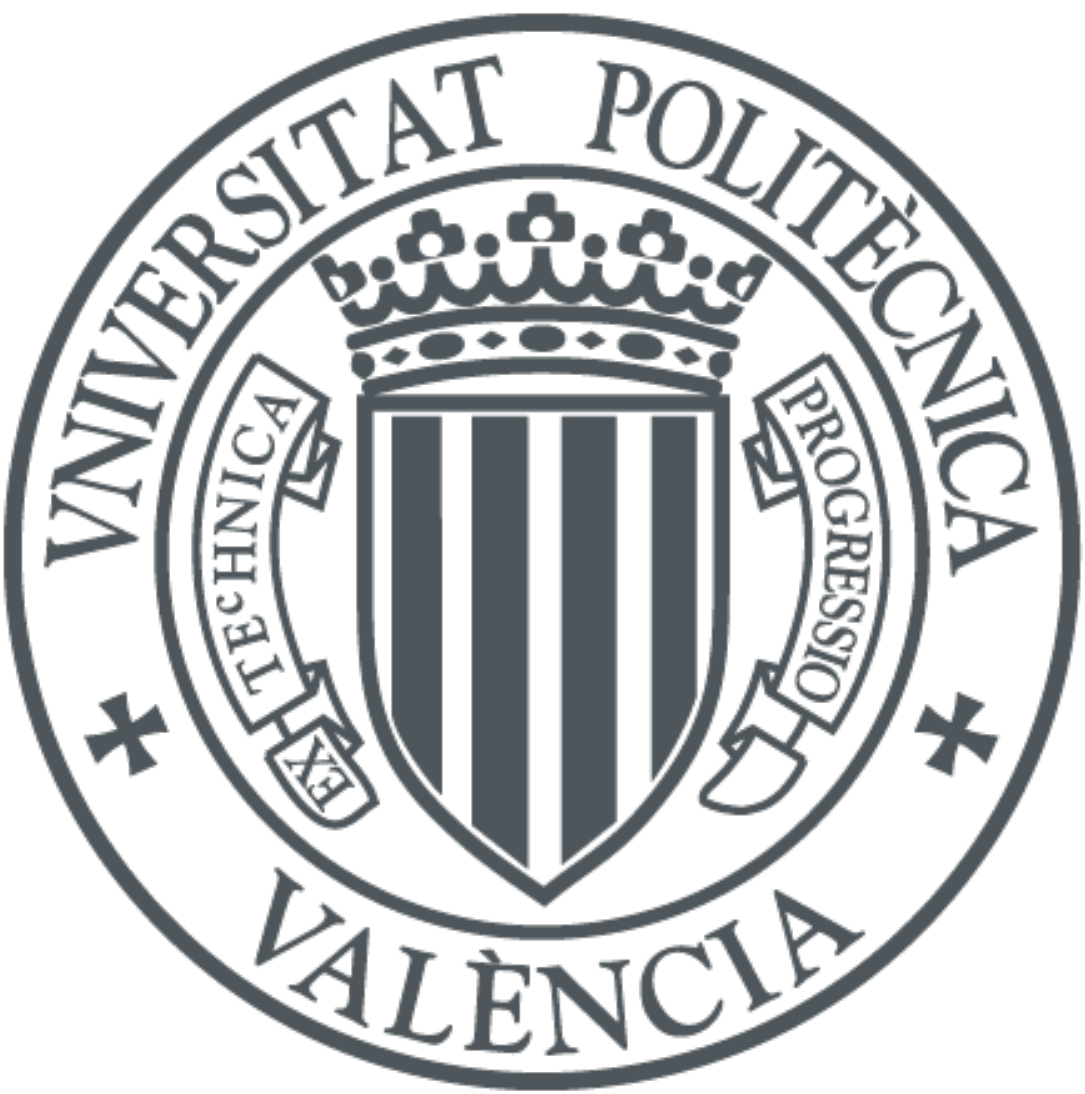

The final publication is available at

http://dx.doi.org/10.1177/0954407014542627

Copyright SAGE Publications (UK and US)

Additional Information 


\section{LARGE EDDY SIMULATION ANALYSIS ON THE INFLUENCE OF NEEDLE LIFT ON CAVITATION IN DIESEL INJECTOR NOZZLES.}

Desantes, J.M. ${ }^{1}$, Salvador, F.J. ${ }^{1}{ }^{*}$ ), Carreres, M. ${ }^{1}$, Martínez-López, J. ${ }^{2}$

${ }^{1}$ CMT-Motores Térmicos, Universitat Politècnica de València

Camino de Vera s/n, E-46022 Spain.

${ }^{2}$ ICON, Berkshire House, Thames Side,

Windsor, Berkshire SL4 1QN, United Kingdom

(*) Corresponding author:

Dr. F. J. Salvador, fsalvado@mot.upv.es

CMT-Motores Térmicos, Universitat Politècnica de València

Camino de Vera s/n, E-46022 Spain.

Telephone: +34-963879659

FAX: +34-963877659 


\section{ABSTRACT}

Cavitation phenomenon has a strong influence on the internal flow and spray development in diesel injector nozzles. Despite its importance, there are lots of aspects which remain still unclear, especially at partial needle lifts when the injector is in the opening and closing phases. For that reason, the current paper is focused on the influence of the needle lift on the internal flow in a diesel nozzle. This study has been carried out with 3D simulations at high injection pressure (160 MPa) using a homogeneous equilibrium model implemented in OpenFOAM to model cavitation phenomenon.

The nozzle has been simulated with LES methods at six different needle lifts $(10,30$, $50,75,100$ and $250 \mu \mathrm{m}$ ), providing relevant information about the evolution of the internal flow, the turbulence development (vorticity, turbulence-cavitation interaction and turbulent structures) and the flow characteristics in the nozzle outlet (mass flow, momentum flux and effective velocity) with the needle position.

\section{KEYWORDS}

Cavitation, needle lift, LES, diesel, nozzle. 


\section{INTRODUCTION}

During the opening and closing processes of a Diesel injector, the flow characteristics at the nozzle exit change significantly as a consequence of the needle movement. This change of flow properties at the exit of the discharge orifices strongly affects the spray pattern and the air-fuel mixing process, and therefore its subsequent combustion $[1][2][3][4][5][6][7][8]$. However, despite its relevance, there are a lot of aspects about the injection process which still remain unsolved, such as the turbulence and cavitation development during the needle movement. This fact is due to the complexity of the internal flow in diesel injection nozzles, characterized by very high velocities (higher than $600 \mathrm{~m} / \mathrm{s}$ ), the transient behaviour of the flow, the small dimensions of the nozzles (whose diameters are usually between 80-200 $\mu \mathrm{m}$ ) and the presence of fuel in vapour phase in cavitating conditions.

Taking into account the increase of injection pulses per cycle during the recent years with pre-injections and post-injections besides the main one, diesel injectors are working most time with partial needle lifts without reaching fully needle lift conditions. This fact has awaken the interest of researchers in the study of the internal flow at partial needle lifts, contributing to the publication of several studies which have demonstrated the importance of the needle position on the internal flow and cavitation phenomenon.

One of the first studies published in this field was performed by Favennec et al. [9], who controlled the needle lift introducing calibrated wedges of different thickness into a Diesel injector. The use of calibrated wedges allowed the calculation of the discharge coefficient in several Valve Covered Orifice nozzles in steady flow conditions at different positions of the needle $(10,25,50,100,200$ and $300 \mu \mathrm{m})$. 
Favennec et al. proved that, without needle, the discharge coefficient increases with the Reynolds number in the non-cavitating regime. This coefficient reached its maximum with the cavitation inception and then decreased as cavitation developed. This behaviour was similar for all pressure conditions, although the discharge coefficient values were lower as the needle lift decreased. For the smallest needle lift, $10 \mu \mathrm{m}$, the behaviour seen was analogous to the rest of lift values if the Reynolds number was changed by modifying the downstream pressure. However, different values were obtained if the Reynolds number was changed through the upstream pressure. This fact seemed to be related to the large deformation of the needle as a consequence of the high injection pressures used in the test.

Arcoumanis et al. [10] also studied the influence of the needle lift using an enlarged transparent model of a six-hole diesel injector nozzle to visualize the cavitating flow. The results obtained from this investigation showed a great influence of the needle position on the cavitation appearance and its length. For high needle lifts, cavitation grew along the upper part of the orifice as a continuous vapour film with a relatively stable behaviour and taking up the $35 \%$ of the cross section of the orifice. The length of the vapour phase decreased as the needle lift was reduced, completely modifying the cavitation appearance (bubbly flow) or even producing the extinction of the cavitation phenomenon. Nevertheless, despite the huge differences found for each needle lift, the critical cavitation number remained almost invariable.

Miranda et al. [11] visualized the internal flow in a real scale diesel injector, replacing the original needle and part of the VCO nozzle by transparent ones. These modifications allowed the visualization of the cavitation in the orifice and the nozzle sac. Miranda et al. observed that cavitation developed in the orifice disappeared for low needle lifts as a 
consequence of a rise of the losses located in the nozzle sac. This fact reduced the velocity and therefore the cavitation number.

Similar work was performed by Badock et al. [12], replacing part of a real one-hole nozzle by a transparent one. Unlike Miranda et al., Badock et al. analysed the cavitation evolution during the opening and closing processes of the injector, taking into account the effects produced by the needle movement. The investigation was focused also on the influence of the vapour bubbles leaving the nozzle on the spray development during the injection process.

Even though all the investigations shown up to this point are completely experimental, interesting computational works about the influence of the needle position on the internal flow have been published as well during the last years. These studies have helped to complement and extend the knowledge on this area.

Massuda et al. [13] published in 2003 a computational work performed in a diesel VCO multi-hole nozzle, modelling the internal flow with AVL-FIRE [14]. In this study, Massuda et al. analysed in detail the transitory behaviour of the cavitation during the opening and closing phases, and investigated the vortex development in the discharge orifices. The velocity, vapour phase and turbulence results at the outlet section of the nozzle were also used as boundary conditions for the simulation of the primary atomization of the spray.

In 2008, Soriano et al. [15] published a computational work performed with Ansys-CFX [16]. This investigation included a validation of mass flow values for different needle lifts against experimental data during the injector opening. This study was completed using the internal flow results for the spray simulation in order to evaluate the penetration and spray angle as well as the droplets size. 
Finally, another interesting investigation was published in 2010 by Som et al. [17], who used FLUENT [18] for the internal flow modelling. Som et al. observed important differences in the cavitation appearance depending on fuel properties and needle position.

Despite the quality of the investigations performed until now, there are a lot of issues related to the influence of the needle position on the internal flow in diesel injector nozzles which remain still unclear. For this reason, the current paper has focused on this topic with LES methods for turbulence modelling, providing relevant information about the turbulence development and its interaction with cavitation phenomenon and the evolution of the flow characteristics (mass flow, momentum flux and effective velocity) with the needle lift.

Apart from the needle lift, which is the main parameter analysed in this research, it is important to remark here how other design parameters such as the rounding radius at the orifice entrance, the conicity of the orifice, the length/diameter ratio, or the orifice inclination respect to the injector axis may affect cavitation.

As published in ([3],[5],[19]) the use of conical orifices or with big rounding curvature radius at the orifice entrance, can reduce or even eliminate cavitation because they induce smooth pressure drop on the flow along the orifice axis. Also, the lower the length/diameter ratio, the higher the cavitation [19]. Finally, regarding the orifice inclination, the higher the inclination of the orifice (reducing the angle respect to the horizontal line), the higher the cavitation intensity expected because of the higher deflection of the streamlines [19].

All these parameters have been kept constant in this study, and so, only the influence of needle lift on cavitation has been analysed in the present investigation. 


\section{NUMERICAL MODEL}

There exist three main approaches for cavitating flow modelling purposes: two phaseflows models [20][21][22][23][24], interface tracking-capturing methods $[25][26][27][28][29][30]$ and continuum flow models or one-fluid models $[31][32][33][34][35][36]$. The first ones treat the liquid and vapour phases separately, solving a set of Navier-Stokes equations for each phase and linking them to mass and momentum transfer terms. Interface tracking and capturing methods assume the cavitating flow as two immiscible phases with different but constant densities, neglecting the viscous effects. For each phase, the model solves the continuity, momentum and energy equations, leaving the interface between both phases aside. The continuum flow models or homogeneous equilibrium models consider the liquid and vapour as a homogeneous mixture of two fluids behaving as one, making it unnecessary to solve the Navier-Stokes equations for each phase. The density of the fluid changes between the density of the pure liquid and pure vapour and it is calculated from an equation of state which generally relates pressure and density. The code used in the present study for modelling cavitating flows is implemented in OpenFOAM ${ }^{\circledR}[37]$. This model, validated in calibrated orifices, one-hole and multihole nozzles by Salvador et al. in its laminar [38][39][40], turbulent RANS [41] and LES [42] versions belongs to the homogeneous equilibrium models (HEM), and therefore assumes the flow as a perfect mixture of liquid and vapour phases in each cell of the domain. In HEM models it is assumed local kinematic equilibrium (local velocity is the same for both phases) and local thermodynamic equilibrium (temperature, pressure and free Gibbs enthalpy equality between phases). This kind of model cannot 
reproduce strong thermodynamic or kinetic non equilibrium effects but, because of its simplicity and numerical stability it is often used for numerical simulations. These last are the main reasons why this model was chosen by the authors.

As stated before, the homogeneous equilibrium model calculates the growth of cavitation using a barotropic equation of state (Eq. 1), which relates pressure and density through the compressibility of the mixture, being the compressibility the inverse of the speed of sound squared (Eq. 2):

$$
\begin{aligned}
& \frac{D \rho}{D t}=\Psi \frac{D p}{D t} \\
& \Psi=\frac{1}{a^{2}}
\end{aligned}
$$

The barotropic equation can be introduced directly in the continuity equation to formulate a pressure equation, and must be consistent with the liquid and vapour equations of state at the limits when there is pure liquid (Eq. 3) or pure vapour (Eq. 4), and also at intermediate states when there is a mixture of both phases.

$$
\begin{aligned}
& \rho_{l}=\rho_{l}^{0}+\Psi_{l} \cdot p \\
& \rho_{v}=\Psi_{v} \cdot p
\end{aligned}
$$

On the other hand, the amount of vapour in the fluid is given by the $\gamma$ parameter (Eq. 5), which is 0 in a flow without cavitation and 1 for fully cavitating flows.

$$
\gamma=\frac{\rho-\rho_{\text {lsat }}}{\rho_{v s a t}-\rho_{\text {lsat }}}
$$

where $\quad \rho_{v s a t}=\Psi_{v} \cdot p_{\text {sat }}$

The fluid density is calculated taking into account the amount of vapour in the fluid $(\gamma)$ together with a correction term based on the pressure (mixture's equilibrium equation of state):

$\rho=\gamma \cdot \rho_{v}+(1-\gamma) \cdot \rho_{l}+\psi\left(p-p_{\text {sat }}\right)$ 
With regard to the mixture's compressibility and viscosity, they are modelled by a simple linear model as a function of the amount of vapour in the fluid:

$$
\begin{aligned}
& \Psi=\gamma \cdot \Psi_{v}+(1-\gamma) \cdot \Psi_{l} \\
& \mu=\gamma \cdot \mu_{v}+(1-\gamma) \cdot \mu_{l}
\end{aligned}
$$

As far as the methodology used by the solver is concerned, the code starts solving the continuity equation for the density (Eq. (10)):

$$
\frac{\partial \rho}{\partial t}+\nabla \cdot(\rho \vec{u})=0
$$

The value of density obtained is used to determine preliminary values of $\gamma$ and $\Psi$ by means of Eq. (5) and Eq. (8), and also to solve the momentum equation (Eq. (11)), which is used to get the matrices used to calculate the pressure-free velocity, $u$ :

$$
\frac{\partial(\rho \vec{u})}{\partial t}+\nabla \cdot\left(\rho \frac{\vec{u} \vec{u}}{2}\right)=-\nabla p+\nabla \cdot(\mu \nabla \vec{u})-\nabla \tau
$$

where $\tau$ represents the subgrid-scale stress used in Large Eddy Simulation techniques. Then, an iterative PISO algorithm is used to solve for $p$ and correct the velocity in order to achieve continuity. The equation solved for the PISO loop is the continuity equation transformed into a pressure equation by using the equation of state (Eq. (7)):

$$
\frac{\partial(\psi p)}{\partial t}-\left(\rho_{l}^{0}+\left(\psi_{l}-\psi_{v}\right) p_{s a t}\right) \frac{\partial \gamma}{\partial t}-p_{s a t} \frac{\partial \psi}{\partial t}+\nabla \cdot(\rho \vec{u})=0
$$

Once continuity has been reached, the amount of vapour, density and compressibility are updated by means of equations (5), (7) and (8), respectively, which are taken into account to solve the momentum equation again, therefore repeating the algorithm until convergence is achieved.

The equations previously described are solved each $\Delta \mathrm{t}$ seconds from $\mathrm{t}=0$ until completing the execution time defined by the user. This parameter, known as time step, has a huge influence on the stability and accuracy of the simulation. The time step is 
calculated based on the Courant number and the Acoustic Courant number, both defined in Eq.(13)and Eq.(14):

$$
\begin{aligned}
& C o=\max \left(\frac{|u|}{\Delta x}\right) \Delta t \\
& C o_{\text {acoustic }}=\max \left(\frac{1}{\sqrt{\psi \Delta x}}\right) \Delta t
\end{aligned}
$$

where $\Delta \mathrm{x}$ represents the length of the cell in the flow direction.

The meaning of the Courant number can be understood as the cell fraction that the flow advances in a time step. This value must be smaller than 1 to ensure the continuous calculation of the flow properties and avoid the risk of losing relevant information. Nevertheless, very small values of this parameter can cause instabilities and an increase of the computational cost. With regard to acoustic Courant number, its meaning is similar to the standard one, but considering the speed of sound in the fluid, evaluated through the compressibility. The values of the maximum Courant number and acoustic Courant number for the simulation shown in this paper are 0.2 and 12.5 respectively, giving a maximum time step of about $3 \mathrm{e}-10$.

\subsection{Turbulence modelling}

It is well known that in turbulence flow the large eddies are unstable and break-up, transferring their energy to smaller eddies. These smaller eddies undergo a similar break-up process, and finally energy is dissipated.

In Large Eddy Simulation the dissipative scales of motion are not completely resolved. That is the reason why a subgrid-scale stress model is used, removing energy from the big scales (which are resolved) and simulating the drain that is associated to the energy cascade [43]. 
In the present paper, the Smagorinsky model has been employed for estimating the $\tau$ parameter used in Eq. (11). This model is one of the most suitable models for modelling channels and internal flow [44]. It belongs to eddy viscosity models and assumes that the anisotropic part of $\tau$ is related to the resolved strain rate field through a scalar eddy viscosity $v_{t}$, which is a function of the local grid length scale $\Delta$ :

$$
\begin{aligned}
& \tau-\frac{1}{3} \operatorname{tr}(\tau) l=-2 v_{t} \bar{S} \\
& v_{t}=l^{2} \operatorname{tr}\left(2 \bar{S}^{2}\right)^{1 / 2}=\left(C_{S} \Delta\right)^{2} \operatorname{tr}\left(2 \bar{S}^{2}\right)^{1 / 2}=\left(C_{S}(\Delta x \Delta y \Delta z)^{1 / 3}\right)^{2} \operatorname{tr}\left(2 \bar{S}^{2}\right)^{1 / 2}
\end{aligned}
$$

The behaviour of the subgrid scales is strongly influenced by the presence of solid boundaries, which alter the exchange mechanism between the big and small eddies and inhibit the growth of small scales. Furthermore, the length scale of the energy-carrying large structures depends on the Reynolds number near the walls [43].

These differences in the behaviour of the subgrid scales near the boundaries force to modify the eddy viscosity used in the Smagorinsky model in the near-wall region. One of the most common models is van Driest damping, where the turbulent mixing length $l$ is modified according to Eq. (17), having only significant effects for $\mathrm{y}^{+}<40$.

$$
l=C_{S} \Delta\left[1-\exp \left(-\left(y^{+} / A^{+}\right)^{3}\right]^{1 / 2}\right.
$$

where $\mathrm{A}^{+}$is constant (its value is 26 ) and $\mathrm{y}^{+}$is the non-dimensional wall-normal distance, defined as:

$\left.y^{+}=y /\left(u_{\tau} / v\right)=y /\left(\sqrt{\tau_{\text {wall }} / \rho}\right) / v\right)$

\section{NUMERICAL SIMULATIONS SET-UP}

\subsection{Nozzle description and mesh parameters}

Figure 1 shows the geometry simulated in the present investigation, which belongs to one of the orifices of a six-holes microsac nozzle. These orifices have an inlet and outlet 
diameter of $170 \mu \mathrm{m}$, a length of $1 \mathrm{~mm}$ and a rounding curvature radius of $13 \mu \mathrm{m}$. This last parameter together with the conicity of the hole has a great influence on the cavitation development as aforementioned in the introduction section [3][5][45][46]. As stated at the end of section 1, the paper deals with the influence of the needle lift on the internal flow, cavitation phenomenon and turbulence development. For that reason, six different needle lift values have been simulated, corresponding to $10,30,50,75,150$ and $250 \mu \mathrm{m}$. It is important to remark that this analysis is based on simulations using different meshes representative of different needle lifts and the actual process is in fact a transient phenomenon affected by the needle movement. Nevertheless, as demonstrated by Martínez-López in his Doctoral Thesis [47], the results provided by this approach are representative of the actual transient injection process, with small differences in terms of mass flow rate, momentum flux and cavitation morphology. In particular, he made a comparison between the results obtained from different simulations using meshes representative of different needle lifts with the results provided by a transient simulation with moving mesh modelling the needle movement. The results obtained in both cases were very similar, with differences lower than $3 \%$ in terms of mass flow or momentum flux and with very similar cavitation appearance (place of apparition and structure evolution).

Each geometry has been meshed discretising the volume in hexahedral cells, keeping a partly structured grid which improves the simulation convergence [19] and a small unstructured region near the orifice inlet.

Despite simulating different needle lifts, the volume occupied by the fluid in the orifice is exactly the same. Thus, the cell size in this zone has been kept constant for all the simulations, ranging from $3 \mu \mathrm{m}(\mathrm{D} / 56.67)$ in the orifice core to $0.6 \mu \mathrm{m}$ in the near wall region with a boundary layer of six layers. Nevertheless, at the nozzle sac and the fluid 
volume between the needle and nozzle wall, the cell size has been fixed to $8 \mu \mathrm{m}$ for fully needle lift conditions $(250 \mu \mathrm{m})$, and it has been reduced as the needle lift decreases, thus providing meshes of around 2100000 cells as a result.

As far as the structure of the mesh is concerned, it has been created trying to get a structured grid that follows as much as possible the direction of the fuel. As can be seen in Figure 2, the only unstructured region in the whole domain corresponds to the orifice entrance. It is important to remark the use of wall functions, which allow avoiding the requirement of $\mathrm{y}^{+<1}$ in the near-wall node. This treatment is designed to reduce the computational cost of the simulations since the resolution of the near wall region of the flow can be very expensive in spite of running them in parallel. As an example of the computational cost of the simulations showed in this paper, each calculated case needs above 90 days to simulate $100 \mu$ s using 30 processors in Tirant supercomputer.

\subsection{Boundary conditions}

One of the most important steps in CFD for ensuring the convergence and the accuracy of the numerical results is the boundary conditions set-up. That is especially critical in the study of multiphase flows and LES calculations.

- Inlet condition.

The treatment of inlet boundary conditions for LES techniques is an extremely complex problem, since in many cases the behaviour of the flow within the domain simulated is largely determined by the inlet behaviour [48][49]. The inlet flow must include a stochastically-varying component, in such a way that the flow structures introduced at the inlet will actually look like turbulence and reproduce the correct turbulence and other mean statistics of the flow [50]. 
However, in some cases the turbulence inlet does not have important effects on the turbulence developed downstream. That is the case of the geometries simulated in the current investigation, where three different inlet conditions have been tested: a fixed pressure value, an inlet with a random noise and a mapped inlet, which uses a precursor calculation to generate inflow conditions and a library of turbulent data which can be introduced into the main domain at the real inlet [49].

The comparison of these methods did not show important differences in terms of internal flow characteristics and cavitation appearance. Nevertheless, the use of precursor simulation methods or the application of a random noise at the inlet boundary increases the computational cost, so a simple fixed pressure value (adjusted to $160 \mathrm{MPa}$ ) has been used for the inlet boundary condition.

- Outlet condition.

The boundary condition at the outlet section, which must simulate the pressure conditions of the combustion chamber, has been fixed to a mean value of $9 \mathrm{MPa}$. The mean pressure condition keeps the mean value desired and allows the existence of very low pressure zones if vapour bubbles reach the hole exit, avoiding the imposition of a rigorous pressure condition that could modify the nature of vapour distributions developed as a consequence of the cavitation phenomenon.

- Walls.

With regard to the walls of the nozzle (needle, orifice, etc.) a non-slip condition for the velocity field has been applied (the fluid will have zero velocity at the solid boundaries), whereas the side walls are defined as symmetry planes. 


\subsection{Numerical schemes}

In contrast to other CFD codes, OpenFOAM allows the discretization of the equations term by term, offering complete freedom for the user to choose the most suitable setup from a wide selection of schemes.

A previous study performed in a real one-holed nozzle (used by the authors in several cavitation studies [38][39][40] has been done in order to check the influence of the numerical schemes available on the convergence, accuracy and computational cost of the simulations. From this study it can be concluded that a Gauss lineal scheme (second order, Gaussian integration) is the most appropriate scheme for the divergence, gradient and laplacian terms. For the interpolation from the cell centers to the face centers a linear scheme (central differencing) has been chosen whereas for the first time derivative a backward scheme (second order, implicit) has been selected.

\subsection{Fluid properties}

With regard to the properties of the fuel used in the present work, the density and viscosity values have been taken from the diesel fuel used in the experimental tests (Repsol CEC RF-06-99) at $23^{\circ} \mathrm{C}$. The compressibility of the liquid phase was calculated from speed of sound measurements whereas the vapour properties have been obtained from a similar fuel from Kärholm et al. in [35]. These values are depicted in Table 1.

\section{RESULTS}

Before analysing in depth the influence of the needle lift on cavitation and turbulence development, a brief validation has been included in the first part of the current section to show the potential of the code for modelling cavitating flows in diesel injection 
nozzles. Additional and extended validation studies performed by the authors with this model can be also found in the literature [38][39][40][41].

After the validation study, the results obtained from the analysis of the influence of the needle lift have been presented, organizing them in three different parts: Cavitation and internal flow development, Characteristics of the flow at the nozzle exit and Turbulence development.

\subsection{Validation at fully needle lift conditions}

The validation has been done comparing the values provided by the CFD code against experimental ones. The experimental data has been obtained using an Injection Rate Discharge Curve Indicator (IRDCI) commercial system and a Momentum flux test rig ([3]) Combining the results provided by both test rigs (mass flow and momentum flux), it is possible to determine the effective velocity at the outlet section of the nozzle.

The results obtained from the computational and the experimental studies have been plotted in the graphs depicted in Figure 3, using a constant injection pressure of 160 $\mathrm{MPa}$ and four different backpressures $(3,5,7$ and $9 \mathrm{MPa})$. For all the pressure conditions, the mean value (averaged in a period equal to 15 times the time needed by a fluid particle to cover the whole orifice) has been represented as a function of the root of pressure drop. This pressure drop is calculated as the difference between the injection pressure and the backpressure.

As can be seen, CFD calculations slightly overestimate the mass flow, momentum flux and effective velocity values obtained experimentally for all the pressure conditions. Attending to the left plot, the mass flow remains collapsed (the values are practically 
constant for all the pressure conditions) for both kinds of measurements with deviations smaller than $10 \%$. This trend indicates that the flow is always at cavitating conditions [39].

Opposite to the mass flow behaviour, the momentum flux does not show any collapse and increases as the backpressure decreases. The reduction of momentum flux justifies the linear increment of the effective velocity with the square root of pressure drop seen in the right plot of Figure 3 since it is calculated dividing the momentum values by the mass flow ones. This velocity rise has been perfectly predicted, being the deviation between the experimental and computational results always lower than 5\%. The behaviour of the flow in terms of effective velocity at the nozzle outlet can be physically justified by the fact that the presence of fuel in vapor phase near the walls reduces the friction losses and the effective diameter for the liquid phase [3].

The agreement between the CFD results and the experimental data can be considered as good enough, considering the experimental uncertainties linked to the determination of the real geometry of the nozzle (used for the CAD model), the uncertainties related to the experimental test rigs used [3] and the complexity of modeling the cavitating flow in diesel injector nozzles (high velocities, biphasic flow, etc.).

\subsection{Cavitation and internal flow development}

The high injection pressure simulated (typical of diesel engines) together with the cylindrical geometry of the nozzle orifice induce the appearance of vapour bubbles in the fluid due to cavitation process [45].

As can be seen in Figure 4, where vapour phase is depicted by means of isosurfaces of $\gamma$ $=0.4$ at fully needle lift conditions $(250 \mu \mathrm{m})$, cavitation is a transient phenomenon, varying its appearance from time step to time step. However, in spite of being a 
transient phenomenon, the origin of the vapour bubbles is always the inlet corner region of the orifice and they develop along the upper surface of the orifice wall reaching the outlet section.

This vapour field is similar to the one seen in the simulations corresponding to needle lifts of 100 and $75 \mu \mathrm{m}$. Nevertheless, for needle lifts lower than $75 \mu \mathrm{m}$, the vapour phase is not only located in the nozzle orifice, but also at the needle seat. As an example of the cavitation at low needle lift, Figure 5 shows the evolution of the vapour phase distribution (isosufaces of $\gamma=0.4$ ) for a lift of $30 \mu \mathrm{m}$. In this case, cavitation takes place in the needle closing, generating vapour bubbles which reach the nozzle hole and enter it through its lower part. The differences between high needle lifts (Figure 4) and low needle lifts (Figure 5) in terms of cavitation become even more important if the orifice is analysed in detail, since for high needle lift the vapour phase only occupies the upper part of the orifice, whereas for low needle lifts vapour bubbles are present in the whole orifice.

The differences found in the cavitation field are a consequence of the change of effective flow area at the seat caused by the variable needle position. This change modifies the pressure evolution and the velocity field of the fluid in the nozzle. For high needle lifts $(75,100$ and $250 \mu \mathrm{m})$, the pressure remains almost constant along the nozzle until reaching the nozzle orifice (see Figure 6). However, as the needle descends, the area between the needle and the nozzle wall decreases, inducing a pressure fall from the inlet boundary and a strong drop in the needle seat (and therefore a phase change due to cavitation phenomenon). Consequently, the flow suffers a great velocity rise in the needle closing, accelerating the fluid and forcing it to enter the orifice through its central and bottom parts. 
One of the best ways to visualise that phenomenon is to depict the path followed by the fluid by means of streamlines. Figure 7 shows the comparison of the velocity field and the streamlines for the needle lifts of $250 \mu \mathrm{m}$ and $30 \mu \mathrm{m}$. This figure remarks the differences stated before about the velocity evolution and the path followed by the fuel, making it quite easy to appreciate that, for $250 \mu \mathrm{m}$, the flow takes up all the volume available between the needle and the nozzle wall before entering the hole through its upper part, whereas for $30 \mu \mathrm{m}$ the fuel tends to flow closer to the needle, arriving almost to the sac and getting into the nozzle orifice through its lower part. Another interesting way to analyse the cavitation development is by means of different cross sections in the nozzle orifice. This kind of pictures makes it possible to study the vapour intensity and distribution in the whole orifice. As a token of that, Figure 8 depicts the cavitation appearance in seven equidistant cross sections for some of the needle lifts simulated $(10,30,50,75$ and $250 \mu \mathrm{m})$. In addition, a general view of the cavitation field in the nozzle has been included for each case to make it straightforward to identify which areas contain fuel in vapour phase.

With regard to the nozzle orifice, the cavitation intensity near the upper inlet radius decreases as the needle descends. The reduction of the cross section in the nozzle seat forces a pressure drop in this area and the modification of the velocity field of the flow. This modification of the velocity field promotes the entry of the fuel in the orifice through its lower and central parts, so the change of direction when the flow is going into the orifice is not as severe as it is for high needle lifts. Thereby the cavitation intensity decreases.

Another important remark to extract from Figure 8 is the absence of vapour in the orifice for the $10 \mu \mathrm{m}$ case. For this needle lift, the section reduction in the seat is so high 
that the flow is not able to recover enough pressure to force cavitation in the lower inlet radius.

\subsection{Characteristics of the flow at the nozzle exit}

Up to this point, the influence of the needle position has been studied only in terms of cavitation appearance, without considering the consequences of the needle lift on the characteristics of the flow at the nozzle outlet, which are essential for the spray development [5][51][52].

It seems obvious that the available area in the needle seat for the flow increases as the needle goes up, so a mass flow rise can be expected. This tendency can be observed in Figure 9, where the averaged mass flow has been plotted as a function of the needle lift. The mass flow increases with a constant slope between 20 and $50 \mu \mathrm{m}$. From a lift of 50 $\mu \mathrm{m}$ the growth rate starts to decrease, being the effects of the needle position from 100 $\mu \mathrm{m}$ almost negligible. Although in Figure 9 the lift where the needle reaches its maximum mass flow corresponds to $100 \mu \mathrm{m}$, this point might actually be located between 75 and $100 \mu \mathrm{m}$. However, this fact has not been checked in detail due to the huge computational cost of each simulation (90 days using 30 processors).

Dividing the mass flow of each simulation by its maximum value (corresponding to 250 $\mu \mathrm{m})$ additional interesting conclusions can be extracted. As can be seen from the right plot of Figure 9, the needle position does not have any influence on the flow characteristics when the needle rises around $40 \%$ of the maximum lift. In the same way, it is important to point out the fact that for a needle lift of $20 \%$ of its maximum, the nozzle is injecting around $72 \%$ of the maximum amount that it is able to inject for the simulated pressure conditions $\left(\mathrm{P}_{\mathrm{inj}}=160 \mathrm{MPa}-\mathrm{P}_{\text {back }}=9 \mathrm{MPa}\right)$. 
As far as the averaged momentum flux evolution is concerned, the trend is similar to the one seen for the mass flow in Figure 9. Indeed, as can be seen in Figure 10, momentum flux increases with the needle lift until reaching $100 \mu \mathrm{m}$, approximately. From this needle lift, the values keep constant near $5 \mathrm{~N}$. Attending to its dimensionless values, it can be noticed that for quite low needle lifts the exit force of the spray is almost the maximum possible for the current working conditions ( $86 \%$ for a needle lift of $30 \%$ ). Finally, with regard to the averaged effective velocity, it shows a similar behavior since it is calculated dividing the momentum flux value by the mass flow one (see Figure 11). From the beginning of the opening process $(10-30 \mu \mathrm{m})$, the velocity reaches values up to $387 \mathrm{~m} / \mathrm{s}$ ( $70 \%$ of the velocity at fully needle lift conditions). In addition, as it happened for the rest of the flow variables analysed in this section, the needle has hardly any influence on the fuel velocity at the nozzle outlet for the last $150 \mu \mathrm{m}$.

A similar behaviour as the one described here in terms of needle lift influence on mass flow, momentum flux and cavitation development are obtained if RANS simulations are performed instead of LES, as shown in [41].

\subsection{Turbulence development}

Considering the pressure conditions simulated in this paper $\left(\mathrm{P}_{\text {inj }}=160 \mathrm{MPa}-\mathrm{P}_{\text {back }}=9\right.$ $\mathrm{MPa}$ ), the Reynolds number is around 9500 at fully needle lift condition, so the flow can be treated as turbulent [45]. The objective of this section is to go in depth in the turbulence development, analyzing its evolution with the needle position attending to two key aspects: the vorticity and the turbulent structures developed. 


\subsubsection{Flow vorticity}

Vorticity is one of the most frequent parameters to study turbulent flows. It describes the local spinning motion of a fluid near some point and it is defined as:

$\omega=|\nabla \times \vec{u}|$

Figures 12, 13 and 14 depict the flow vorticity and the vapour phase for three different needle lifts: 250,75 and $30 \mu \mathrm{m}$. For each needle lift, both fields have been represented in the mean plane of the nozzle for three different time steps, delayed by $0.5 \mu \mathrm{s}$. At fully needle lift condition, the vorticity of the fuel is almost zero in the zone upstream the orifice (feeding channel and sac volume). Once inside the orifice, the highest values are found in the upper part. As can be seen in the lower pictures of Figure 11, the upper part of the orifice also corresponds to the zone with fuel in vapour phase due to the cavitation developed on the curvature radius.

As the needle lift decreases, the vorticity upstream the orifice increases (see Figure 13). At the beginning, the highest values of vorticity are found near the needle wall, whereas the values near the nozzle wall are almost negligible. However, for the lowest values of needle lift (Figure 14), the zone with high vorticity extends to the whole section between the needle and the nozzle wall and an increase of the maximum level is detected. This trend is consequence of the cavitation intensity rise in the seat when the needle descends.

The relationship between vorticity and cavitation can also be proved analyzing their evolution in the nozzle orifice. For high needle lifts, the highest turbulence levels are located in the upper part of the orifice, whereas for low needle lifts $(50$ and $30 \mu \mathrm{m})$ they can be found in the central and lower parts. In overall terms, the highest turbulence levels are found in the liquid-vapour interface. 
Nevertheless, the turbulence rise is not always produced by cavitation phenomenon.

That fact can be demonstrated by taking a look at the nozzle sac. The vorticity increases significantly as the needle lift decreases even though there is not fuel in vapour phase in the sac. When the needle descends, the cross section in the nozzle seat decreases and the velocity of the fuel increases. In that situation, the fuel tends to flow faster following the needle profile and arrives to the nozzle sac with higher velocities before reaching the orifice. For that reason, a turbulence rise can be expected in this zone.

\subsubsection{Turbulent structures}

In the previous section it was possible to confirm that cavitation promotes the turbulence development and vortex formation as a consequence of the high velocities and the abrupt changes of section and direction of the flow. In order to complete this study, it is also interesting to analyse in depth the turbulent structures development and to characterize their evolution within the nozzle.

One of the most extended approaches to identify turbulent structures is the second invariant of the velocity [53][54], usually known as Q (see Eq. (20)). This approach allows the identification of the flow structures dominated by a strong rotation.

$Q=\omega^{2}-\nabla \vec{u} \cdot \nabla \vec{u}$

Figure 15 shows the turbulent structures predicted by the code for three different needle lifts $(10,30$ and $250 \mu \mathrm{m})$ by means of isosurfaces of $\mathrm{Q}>1.53 \cdot 10^{15} s^{-2}$ coloured according to the flow velocity. These isosurfaces, represented for the right half part of the nozzle, have been marked with black lines in the mean plane to make it easier to visualize the structures.

For fully needle lift conditions $(250 \mu \mathrm{m})$, the size of the vortexes located at the nozzle seat and near the sac is quite bigger than those ones existing in the orifice. The eddies 
developed upstream the orifice show structures with considerable lengths and sizes. Nevertheless, their sizes and lengths decrease as the flow advances, promoting the existence of tiny eddies near the nozzle exit due to cavitation phenomenon.

For a lower needle lift $(30 \mu \mathrm{m})$, the size of the structures located in the sac decreases since the available volume for its development is also smaller. This fact, together with the cavitation process in the seat, contributes to the existence of very small eddies in the sac and the orifice inlet. Once the flow goes into the orifice, the vortexes continue breaking down into smaller structures as a consequence of the cavitation existing in the central part of the orifice. This process continues until the fuel reaches the outlet section.

The trend seen for 250 and $30 \mu \mathrm{m}$ strengthens for a needle position closer to the total injector closing $(10 \mu \mathrm{m})$, with very small vortexes from the nozzle seat to the outlet section. Only the eddies located in the sac are bigger due to the lower velocity of the flow in this zone and the increase of the available volume for their development. It is important to remark that although cavitation in the orifice is almost negligible compared to the two other cases, the reduction of the cross section in the needle seat and the cavitation intensity in this area are enough to generate tiny vortexes in the entire orifice.

\section{CONCLUSIONS}

The present investigation has focused on the influence of the needle lift on the internal flow and cavitation phenomenon in a diesel injector nozzle. This study has been performed simulating six different needle lifts at high injection pressure using Large Eddy Simulation methods via OpenFOAM. The main conclusions obtained are as follows: 
- Cavitation is a transient phenomenon varying its appearance from time step to time step.

- For high needle lifts, the vapour flows along the upper surface of the orifice from the inlet rounding radius to the outlet section of the orifice, whereas for low needle lifts cavitation is located at the needle seat and at the lower part of the orifice.

- Mass flow, momentum flux and effective velocity increase as the needle lift increases. However, when the needle reaches a lift of $40 \%$ of the maximum needle lift, the needle stops having an influence on the flow characteristics at the nozzle outlet.

- At fully needle lift condition, the vorticity of the flow is almost negligible upstream the orifice. Once inside the orifice, the highest values can be seen in the upper part of the orifice where cavitation develops, especially in the liquidvapour interface.

- The turbulence upstream the orifice and in the nozzle sac increases as the needle lift decreases. Furthermore, a change of the highest turbulent intensity zone can be noticed since the highest vorticity values can be found in the central and bottom parts of the orifice (zones where cavitation appears).

- The needle descent promotes the increase of eddies and the vortexes break into smaller structures due to cavitation phenomenon and the reduction of the cross section in the needle seat.

\section{ACKNOWLEDGMENTS}


The authors would like to thank the computer resources, technical expertise and assistance provided by the Universidad de Valencia in the use of the supercomputer "Tirant".

\section{REFERENCES}

[1] Faeth, G.M., Hsiang, L-P., Wu, P-K., 1995. Structure and Breakup Properties of Sprays, International Journal of Multiphase Flow. 21, 99-127.

[2] Park, S.H., Suh, H.K., Lee, C.S., 2009. Effect of bioethanol-biodiesel blending ratio on fuel spray behavior and atomization characteristics, Energy \& Fuels. 23, 4092-4098.

[3] Payri, R., García, J.M., Salvador, F.J., Gimeno, J., 2005. Using spray momentum flux measurements to understand the influence of diesel nozzle geometry on spray characteristics, Fuel. 84, 551-561.

[4] Suh, H.K., Lee, C.S., 2008. Effect of cavitation in nozzle orifice on the diesel fuel atomization characteristics, International journal of heat and fluid flow. 29, 1001-1009.

[5] Payri, R., Salvador, F.J., Gimeno, J., De la Morena, J., 2009. Effects of nozzle geometry on direct injection diesel engine combustion process, Applied thermal engineering. 29, 2051-2060.

[6] Park, S.H., Kim, S.H., Lee, C.S., 2009. Mixing stability and spray behavior characteristics of diesel-ethanol-methyl ester blended fuels in a common-rail diesel injection system, Energy \& Fuels. 23, 5228-5235.

[7] Desantes, J.M., Payri, R., Salvador, F.J., Gil, A., 2006. Development and validation of a theoretical model for diesel spray penetration, Fuel. 85, 910-917. 
[8] Desantes, J.M., Payri, R., García, J.M., Salvador, F.J., 2007. A contribution to the understanding of isothermal diesel spray dynamics, Fuel. 86, 1093-1101.

[9] Favennec, A., Fruman, D., 1999. Effect of the needle position on the cavitation of Diesel injectors, Proceedings of the 3rd ASME/JSME Joint Fluids Engineering Conference, San Francisco.

[10] Arcoumanis, C., Flora, H., Gavaises, M., Kampanis, N., Horrocks, R., 1999. Investigation of cavitation in a vertical multi-hole Diesel injector, SAE Paper 1999-01-0524.

[11] Miranda, R., Chaves, H., Martin, U., Obermeier, F., 2003. Cavitation in a Transparent Real Size VCO Injection Nozzle, Proceedings of ICLASS, Sorrento Italy.

[12] Badock, C., Wirth, R., Fath, A., Leipertz, A., 1999. Investigation of cavitation in real size diesel injection nozzles, International journal of heat and fluid flow. 20(5), 538-544.

[13] Masuda, R., Fuyuto, T., Nagaoka, M., 2005. Validation of a diesel fuel spray and mixture formation from nozzle internal flow calculation, SAE paper 2005-01-2098.

[14] AVL-FIRE User Manual, V. 8.4.2., AVL-List Gmbh, 2006.

[15] Soriano, O., Sommerfeld, M., Burkhardt, A., 2008. Validation of a cavitation and turbulence induced model for the primary breakup of diesel jets, ILASS, Como Lake, Italy.

[16] ANSYS CFX-Solver Theory Guide, Ansys Europe, Ltd. 2006.

[17] Som, S., Aggarwal, S., El-Hannouny, E., Longman, D., 2010.

Investigation of nozzle flow and cavitation characteristics in a diesel injector, Journal of Engineering for Gas Turbines and Power. 132(4), 042802. 
of the Influence of Diesel Nozzle Geometry on the inception of Cavitation, Atomization and Sprays. 13, 579-604. in nozzles using the two-fluid model, Proc. 7th Annu. Conf. Comp. Fluid Dyn. Soc. Canada, Halifax, NS, Canada (ed. J. Militzer), 7-3.

[21] Grogger, H., Alajbegovic, A., 1998. Calculation of the cavitating flow in venturi geometries using two fluid model, ASME Paper FEDSM 98, 5295. Alajbegovic, A., Meister, G., Greif, D., Basara, B., 2002. Three phase cavitating flows in high-pressure swirl injectors, Experimental thermal and fluid science. 26(6), 677-681.

[23] Lambert, L., 1997. Modelisation des jets d'injection haute pression des moteurs Diesel et validation experimentale, $\mathrm{PhD}$ Thesis, Institut français du pétrole.

[24] Giannadakis, E., Papoulias, D., Gavaises, M., Arcoumanis, C., 2007. Evaluation of the predictive capability of diesel nozzle cavitation models, SAE paper 2007-01, 0245.

[25] Unverdi, S., Tryggvason, G., 1992. A front-tracking method for viscous, incompressible, multi-fluid flows, Journal of Computational Physics. 100(1), 2537.

[26] Brackbill, J., Kothe, D., Zemach, C., 1992. A continuum method for modeling surface tension, Journal of computational physics. 100(2), 335-354.

[27] Tomiyama, A., Makino, Y., Zun, I., Sakaguchi, T., 1998. Bubble shape modelling for a 3d two-way bubble tracking method, ICMF'98, Lyon, France. 
[28] Befrui, B., Corbinelli, G., D’Onofrio, M., Varble, D., 2011. GDI MultiHole Injector Internal Flow and Spray Analysis, SAE 2011-01-1211 1, 1211.

[29] Befrui, B., Corbinelli, G., Robart, D., Reckers, W., Weller, H., 2008.

LES Simulation of the internal flow and near-filed spray structure of an outward-opening GDi injector and comparison with imaging data, SAE 200801-0137.

[30] Marcer, R., Le Cottier, P., Chaves, H., Argueyrolles, B., Habchi, C., Barbeau, B., 2000. A validated numerical simulation of diesel injector flow using a VOF method, SAE transactions 109(3), 2099-2118.

[31] Delannoy, Y., 1990. Two-phase flow approach in unsteady cavitation modelling, Proc. ASME FED 98, 153-158.

[32] Plesset, M., Devine, R., 1965. Effect of exposure time on cavitation damage, Inf. téc. DTIC Document.

[33] Chen, Y., Heister, S., 1996. Modeling cavitating flows in diesel injectors, Atomization and Sprays. 6, 709-726.

[34] Vortmann, C., Schnerr, G.H., Seelecke, S., 2003. Thermodynamic modeling and simulation of cavitating nozzle flow, International Journal of Heat and Fluid Flow 24, 774-783.

[35] Kärholm, F., Nordin, P., Weller, H., 2007. Modelling injector flow including cavitation effects for diesel applications, ASME Fluids Engineering Conference.

[36] Echouchene, F., Belmabrouk, H., Le Penven, L., Buffat, M., 2011. International Journal of Heat and Fluid Flow 32(5), 1068-1075. OpenFOAM ${ }^{\circledR}$ is a registered trade mark of OpenCFD Limited http://www.opencfd.co.uk/openfoam/index.html 
Salvador, F.J., Romero, J.-V., Roselló, M.-D., Martínez-López, J., 2010.

Validation of a code to model cavitation phenomena in Diesel injector nozzles, Mathematical and Computer Modelling. 52, 1123-1132.

[39] Salvador, F.J., Hoyas, S., Novella, R., Martínez-López, J., 2011.

Numerical simulation and extended validation of two-phase compressible flow in Diesel injector nozzle, Proceedings of the Institution of Mechanical

Engineers, Part D, Journal of Automobile Engineering. 225, 545-563.

[40] Payri, F., Payri, R., Salvador, F.J., Martínez-López, J., 2012. A

contribution to the understanding of cavitation effects in Diesel injector nozzles through a combined experimental and computational investigation. Computers \& Fluids. 58, 88-101.

[41] Salvador, F.J., Martínez-López, J., Caballer, M., De Alfonso, C., 2012. Study of the influence of the needle lift on the internal flow and cavitation phenomenon in diesel injector nozzles by CFD using RANS methods, Energy Conversion and Management. 66, 246-256.

[42] Salvador, F.J., Martínez-López, J., Romero, J.V., Roselló, M.D., 2013. Computational study of the cavitation phenomenon and its interaction with the turbulence developed in diesel injector nozzles by Large Eddy Simulation (LES), Mathematical and Computer Modelling. 57(7-8), 1656-1662.

[43] Piomelly, U., 1999. Large-eddy simulation: achievements and challenges, Progress in Aerospace Sciences. 335-362.

[44] Launder, B., Spalding, D., 1971. The numerical computation of turbulent flow, Comp. Meth. In Appl. Mech. Eng. 3, 269. 

cavitation on the internal flow and the spray characteristics in diesel injection nozzles, Fuel. 83, 419-431.

[46] Payri, R., Salvador, F.J., Gimeno, J., De la Morena, J., 2009. Study of cavitation phenomena based on a technique for visualizing bubbles in a liquid pressurized chamber, International Journal of Heat and Fluid Flow 30(4), 768777.

[47] Martínez-López, J. 2013. Estudio computacional de la influencia del levantamiento de aguja sobre el flujo interno y el fenómeno de la cavitación en toberas de inyección diesel. Doctoral Thesis, Universitat politécnica de València.

[48] Tabor, G., Baba-Ahmadi, M., 2010. Inlet conditions for large eddy simulation: A review, Computer and Fluids. 39, 553-567.

[49] Payri, R., Gimeno, J., Marti-Aldaravi, P., Bracho, G., 2011. Study of the influence of the inlet boundary conditions in a LES simulation of internal flow in a diesel injector, Mathematical and Computer Modelling. 57(7-8), 1709-1715.

[50] De Villiers, E., 2006. The Potential of Large Eddy Simulation for the Modeling of Wall Bounded Flows, PhD Thesis, Imperial College of Science, Technology and Medicine.

[51] Lee, J., Min, K., Kang, K., Bae, C., Giannadakis, E., Gavaises, M., Arcoumanis, C., 2006. Effect of piezo-driven and solenoid-driven needle opening of common-rail diesel injectors on internal nozzle flow and spray development, International Journal of Engine Research. 7(6), 489-502. 
Influence of cavitation phenomenon on primary break-up and spray behavior at stationary conditions, Fuel. 89, 3033-3041.

[53] Lesieur, M., Métais, O., Comte, P., 2005. Large Eddy Simulation of turbulence, Ed. Cambridge.

[54] Sagaut, P., 2001. Large Eddy Simulation for incompressible flows, Springer, Berlin.

\section{LIST OF TABLES AND FIGURE CAPTIONS}

Table 1. Fluid properties.

Figure 1. Simulated nozzle (fully needle lift condition).

Figure 2. Detailed views of the mesh: orifice inlet and curvature radius (upper), orifice inlet and part of the sac (lower) and orifice outlet (right).

Figure 3. Comparison of experimental and CFD results at fully needle lift conditions.

Figure 4. Isosurfaces of $\gamma=0.4$ at fully needle lift conditions $(250 \mu \mathrm{m})$.

Figure 5. Isosurfaces of $\gamma=0.4$ at a needle lift of $30 \mu \mathrm{m}$ for three different time steps. Figure 6. Pressure field in the mean plane of the nozzle for needle lifts of $250 \mu \mathrm{m}$ (left) and $30 \mu \mathrm{m}$ (right).

Figure 7. Velocity field and streamlines for $250 \mu \mathrm{m}$ and $30 \mu \mathrm{m}$.

Figure 8. Cavitation fraction $(\gamma)$ for $10,30,50,75$ and $250 \mu \mathrm{m}$.

Figure 9. Mass flow against needle lift: real values and dimensionless ones.

Figure 10. Momentum flux against needle lift: real values and dimensionless ones. 
Figure 11. Effective velocity against needle lift: real values and dimensionless ones.

Figure 12. Vorticity and vapour phase field in the mean plane of the nozzle for three different time steps for a needle lift of $250 \mu \mathrm{m}$.

Figure 13. Vorticity and vapour phase field in the mean plane of the nozzle for three different time steps for a needle lift of $75 \mu \mathrm{m}$.

Figure 14. Vorticity and vapour phase field in the mean plane of the nozzle for three different time steps for a needle lift of $30 \mu \mathrm{m}$.

Figure 15. Isosurfaces of $\mathrm{Q}>1.53 \cdot 10^{15} \mathrm{~s}^{-2}$ coloured by the velocity field.

\begin{tabular}{|c|c|c|}
\hline & Liquid phase & Vapour phase \\
\hline Density $\left(\mathrm{kg} / \mathrm{m}^{3}\right)$ & 830 & 0.1361 \\
\hline Viscosity $\left(\mathrm{kg} / \mathrm{ms}^{2}\right)$ & $3.6710^{-3}$ & $5.9510^{-6}$ \\
\hline Compressibility $\left(\mathrm{s}^{2} / \mathrm{m}^{2}\right)$ & $510^{-7}$ & $2.510^{-6}$ \\
\hline Saturation Pressure $(\mathrm{Pa})$ & \multicolumn{2}{|c|}{5400} \\
\hline
\end{tabular}

Table 1. Fluid properties. 


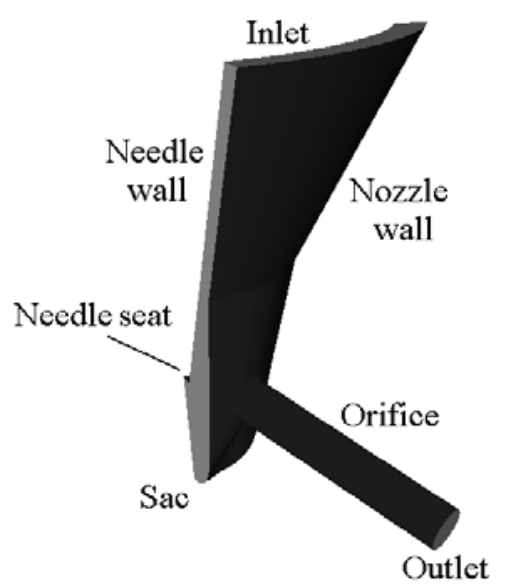

Figure 1. Simulated nozzle (fully needle lift condition). 


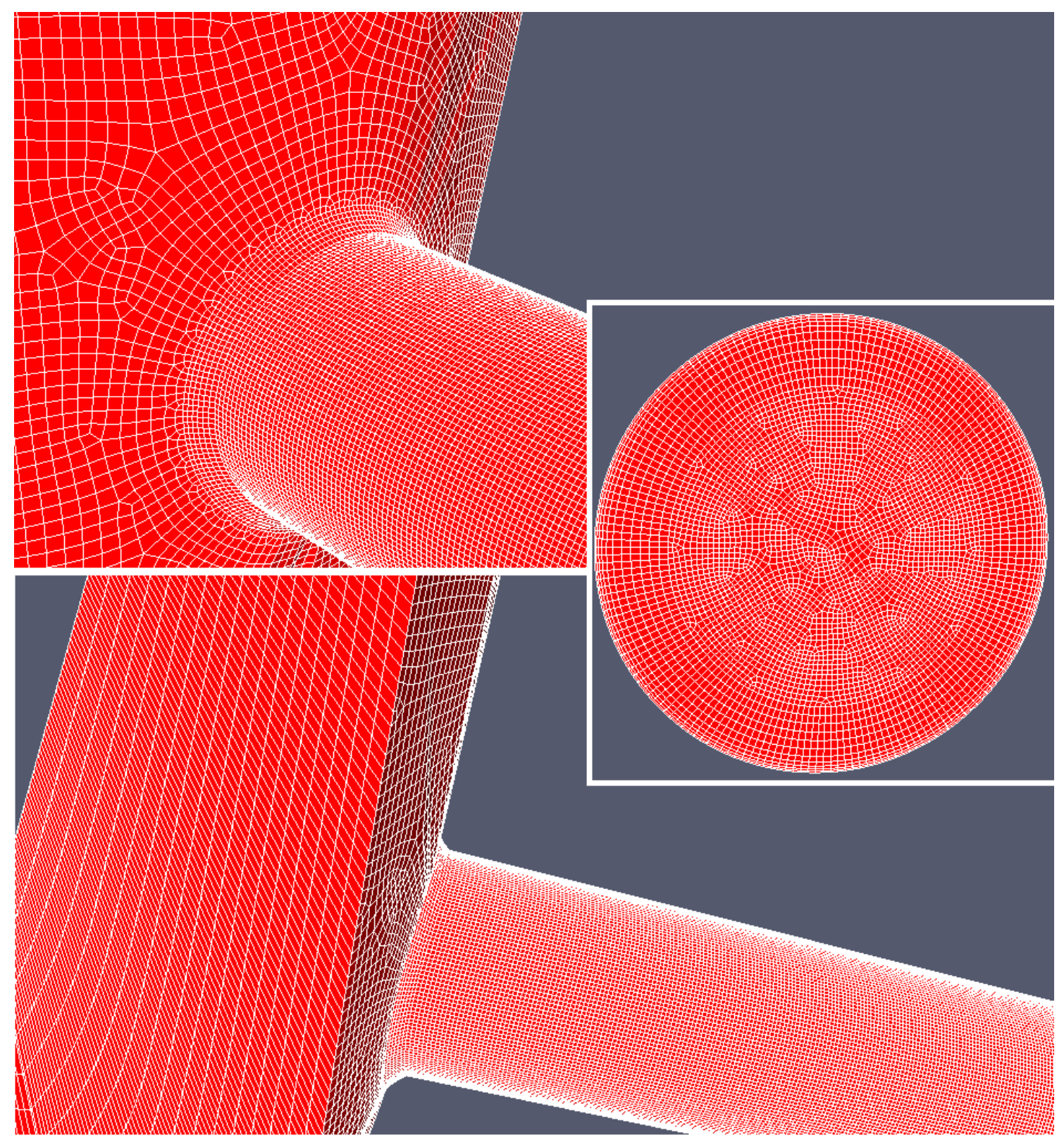

Figure 2. Detailed views of the mesh: orifice inlet and curvature radius (upper), orifice inlet and part of the sac (lower) and orifice outlet (right). 

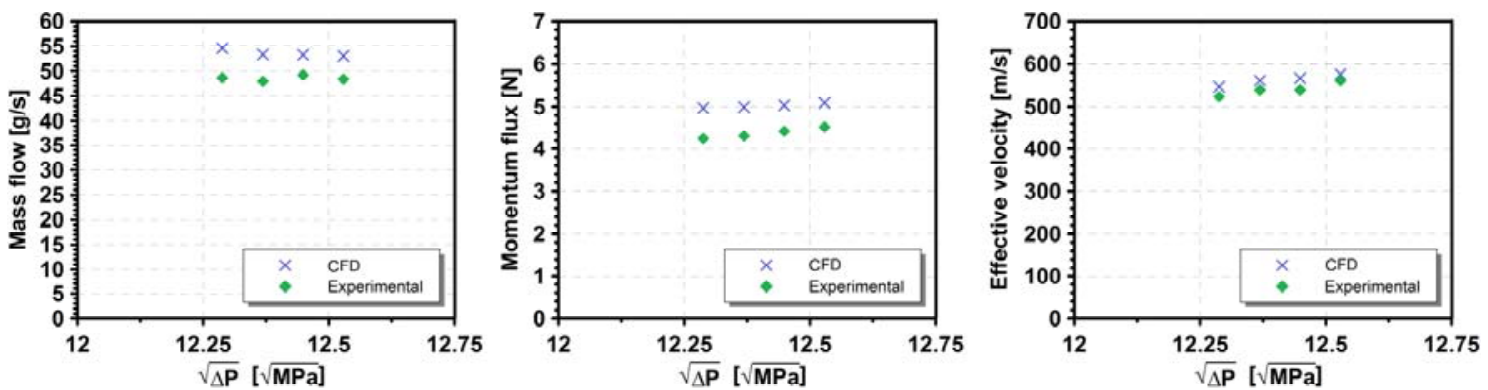

Figure 3. Comparison of experimental and CFD results at fully needle lift conditions. 


\section{$250 \mu \mathrm{m}$}
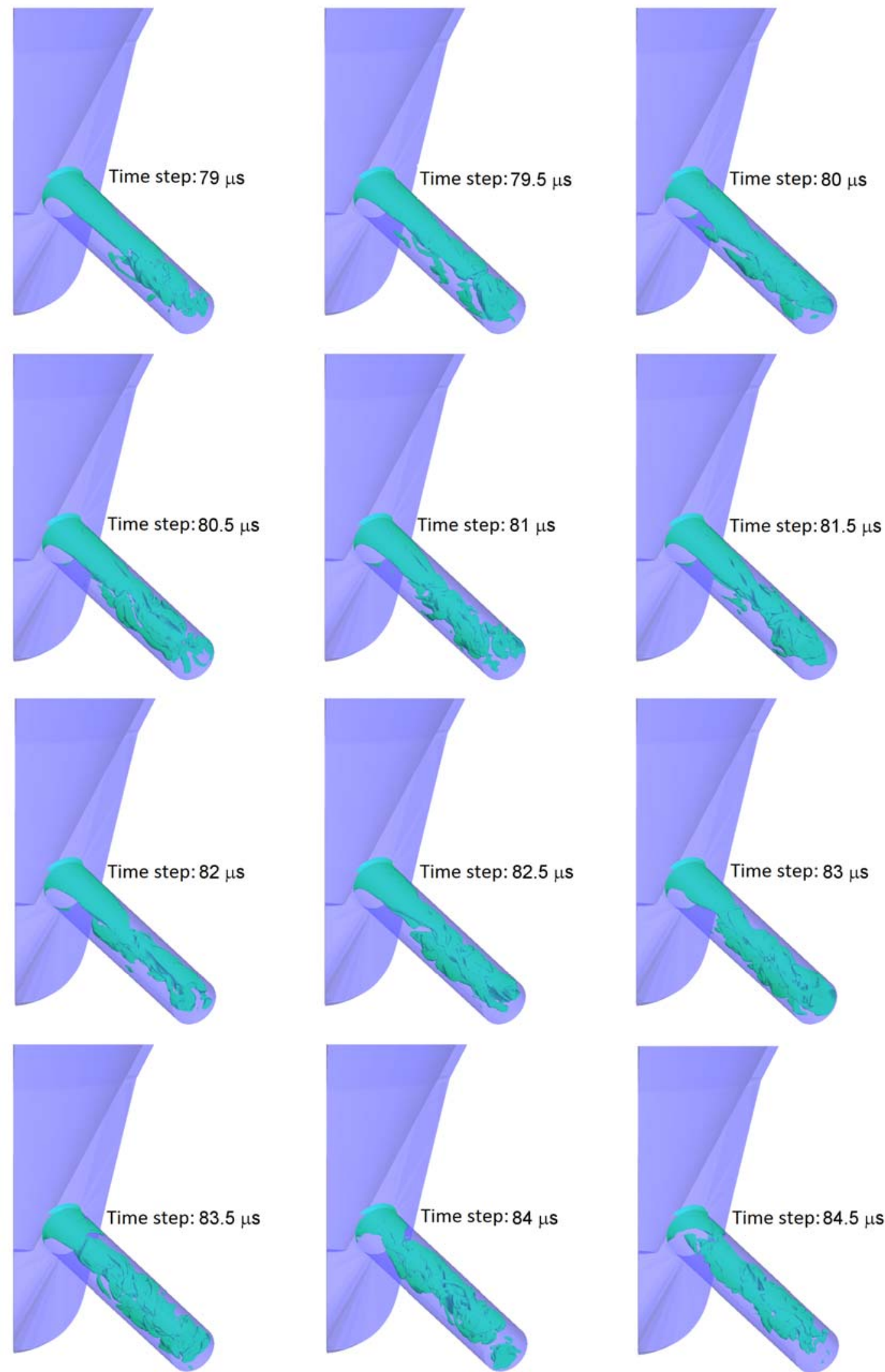

Figure 4. Isosurfaces of $\gamma=0.4$ at fully needle lift conditions $(250 \mu \mathrm{m})$. 


\section{$30 \mu \mathrm{m}$}
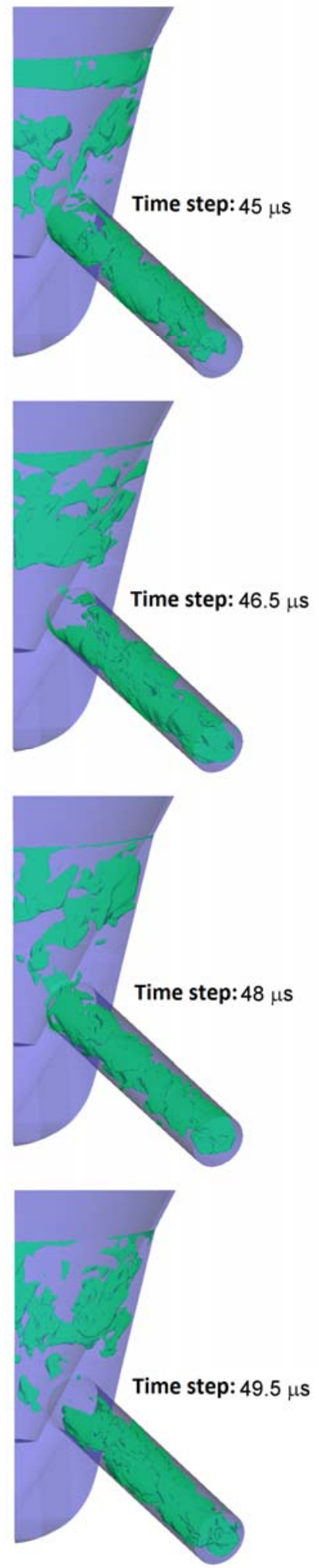
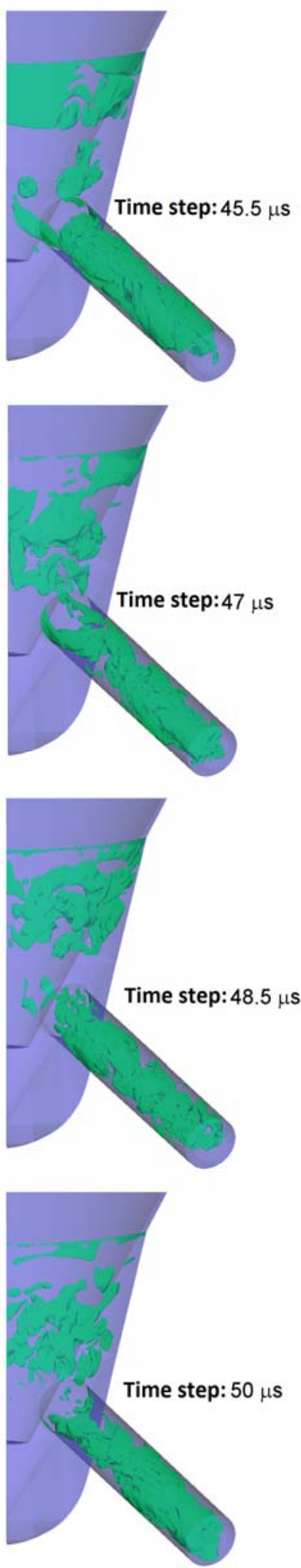
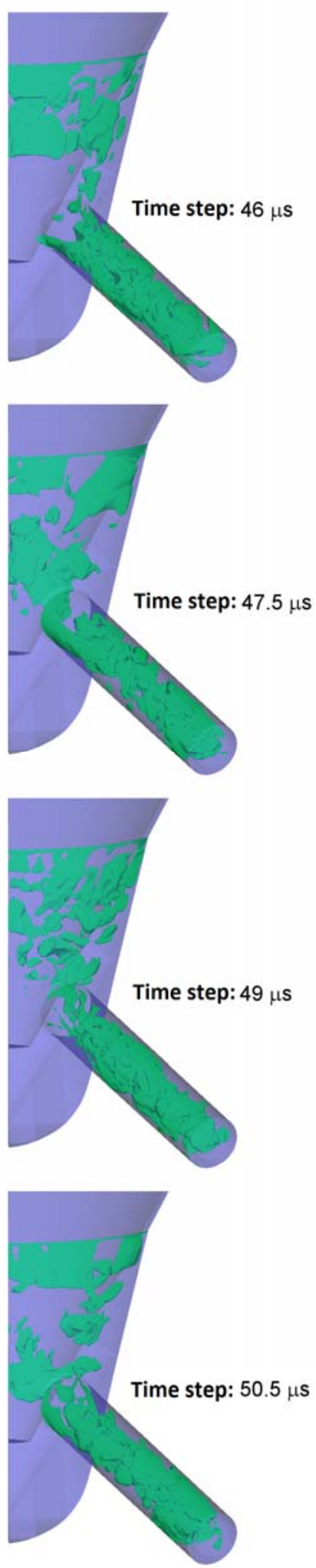

Figure 5. Isosurfaces of $\gamma=0.4$ at a needle lift of $30 \mu \mathrm{m}$. 


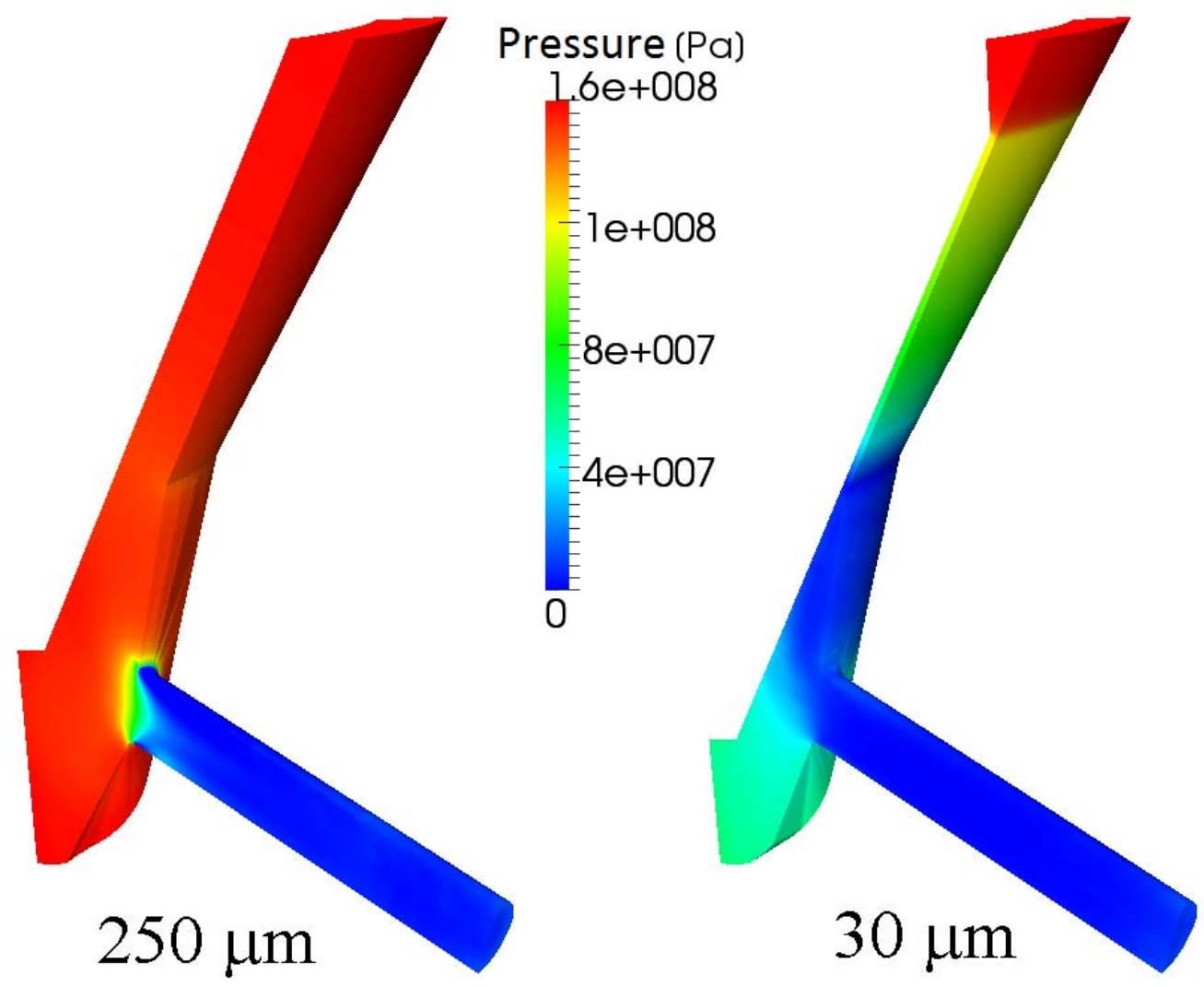

Figure 6. Pressure field in the mean plane of the nozzle for needle lifts of $250 \mu \mathrm{m}$ (left) and $30 \mu \mathrm{m}$ (right). 

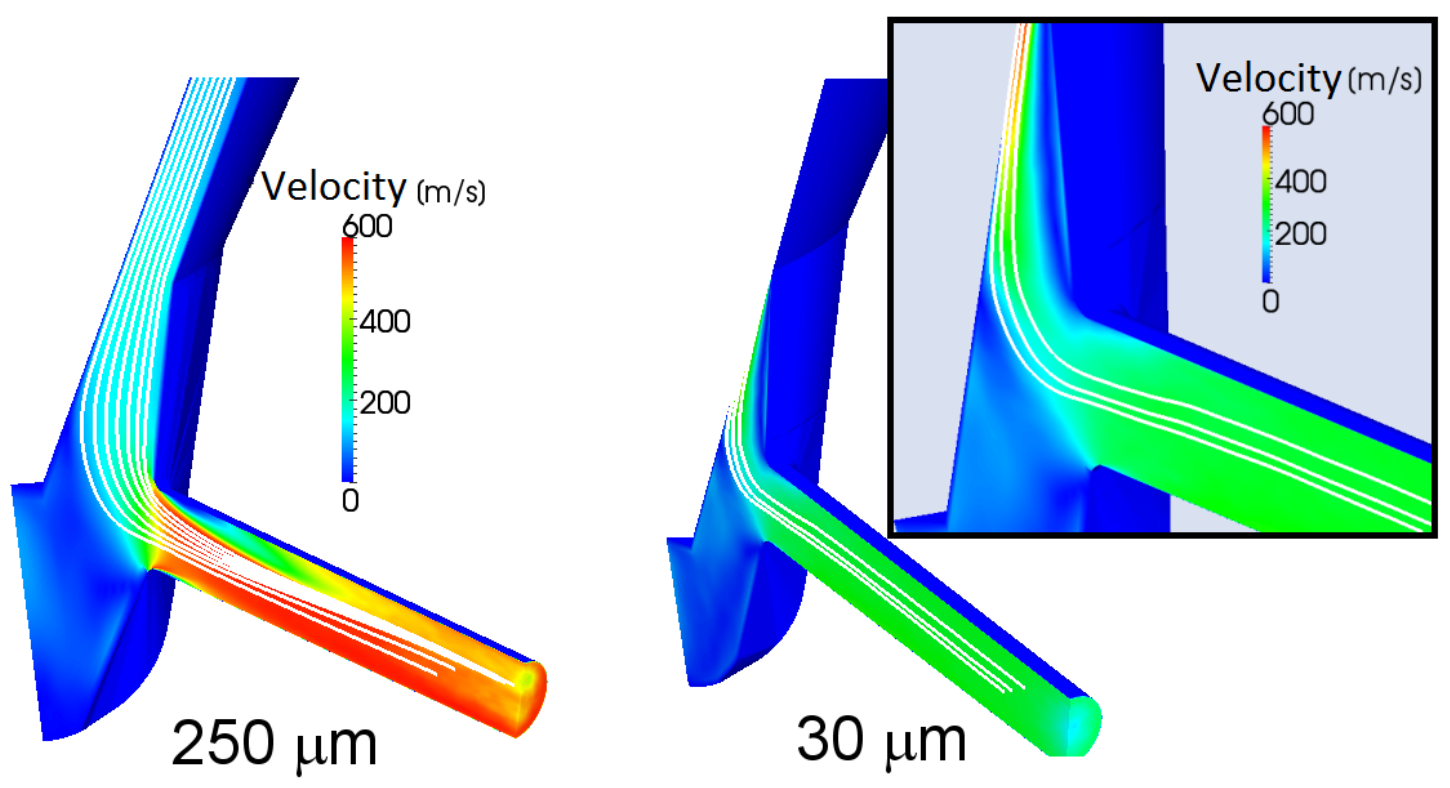

Figure 7. Velocity field and streamlines for $250 \mu \mathrm{m}$ and $30 \mu \mathrm{m}$. 

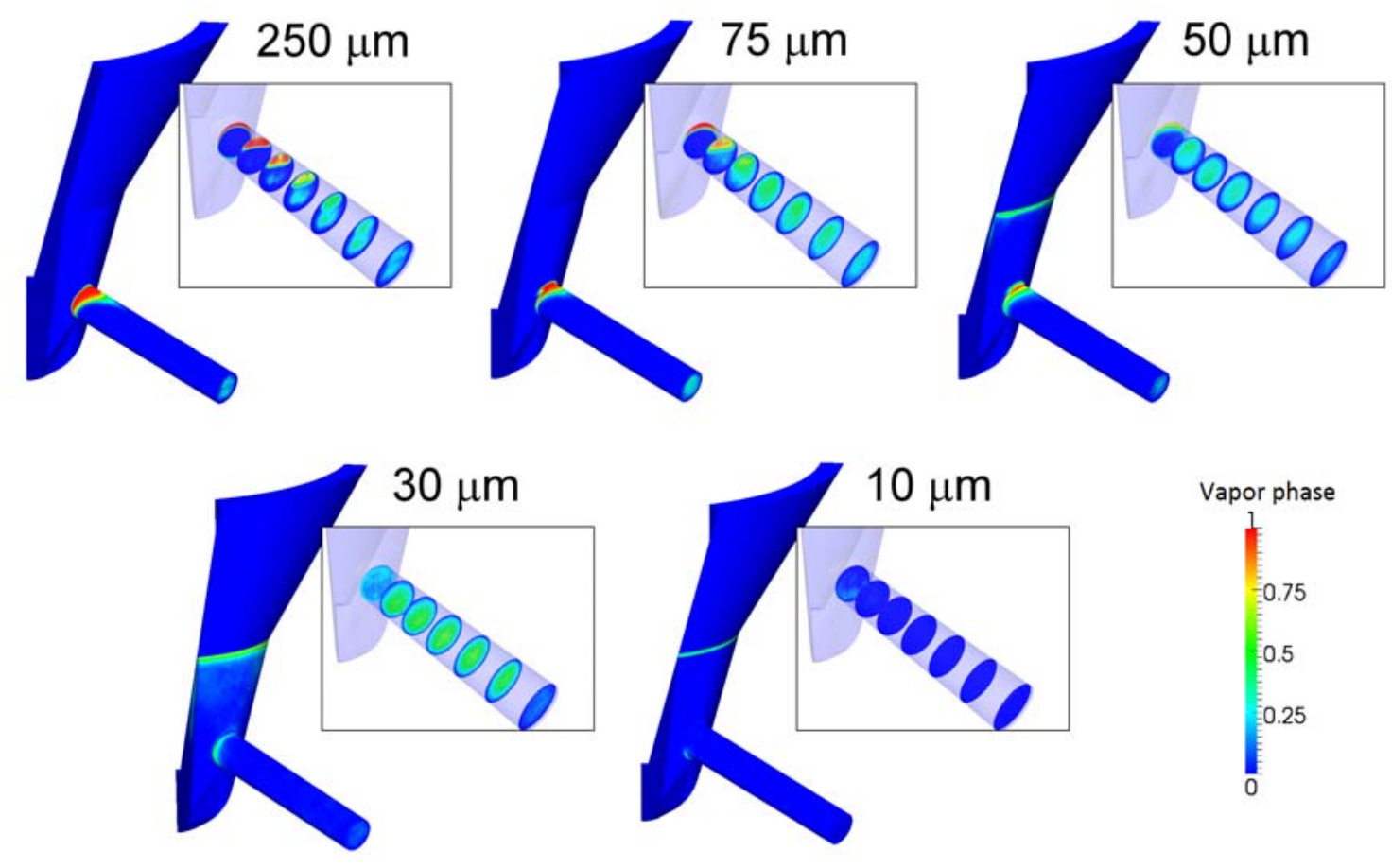

Figure 8. Vapour fraction $(\gamma)$ for 10, 30, 50, 75 and $250 \mu \mathrm{m}$. 

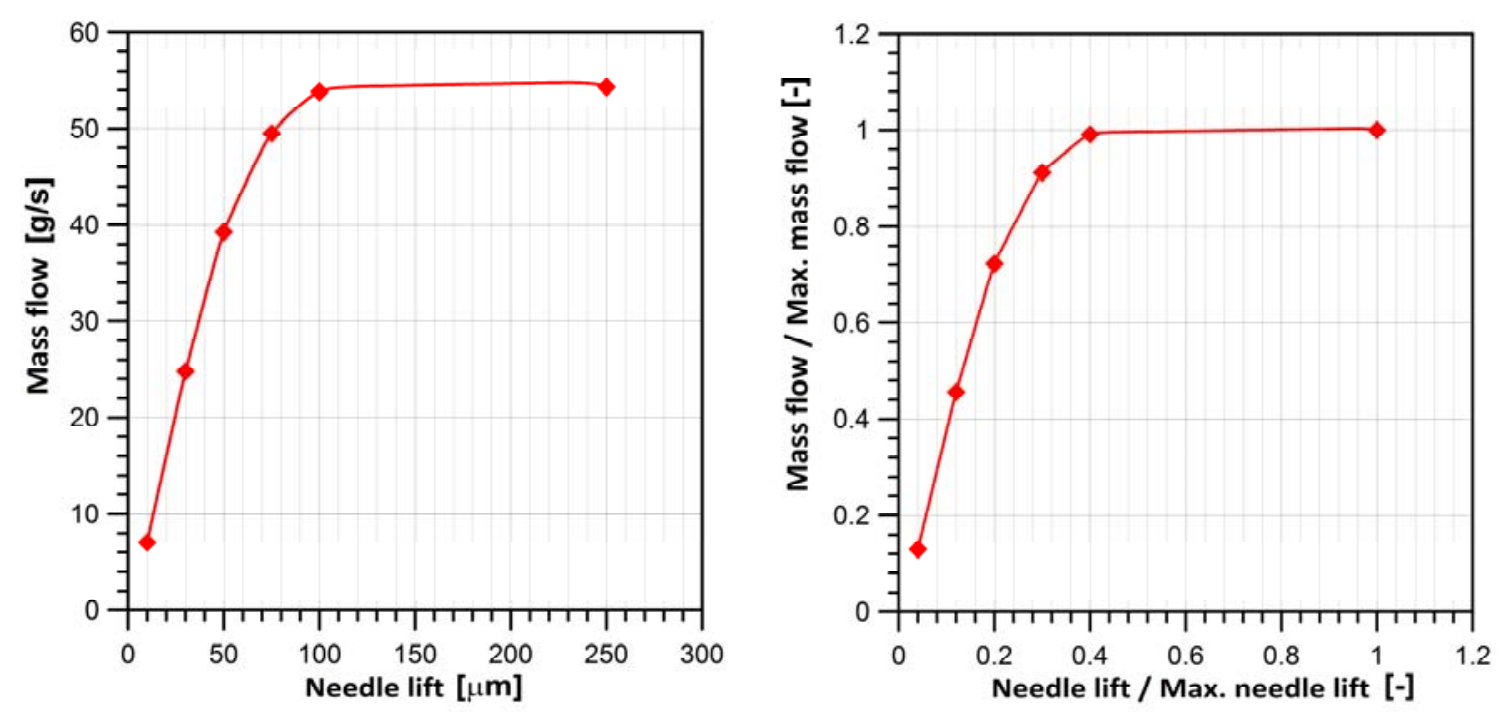

Figure 9. Mass flow against needle lift: real values and dimensionless ones. 

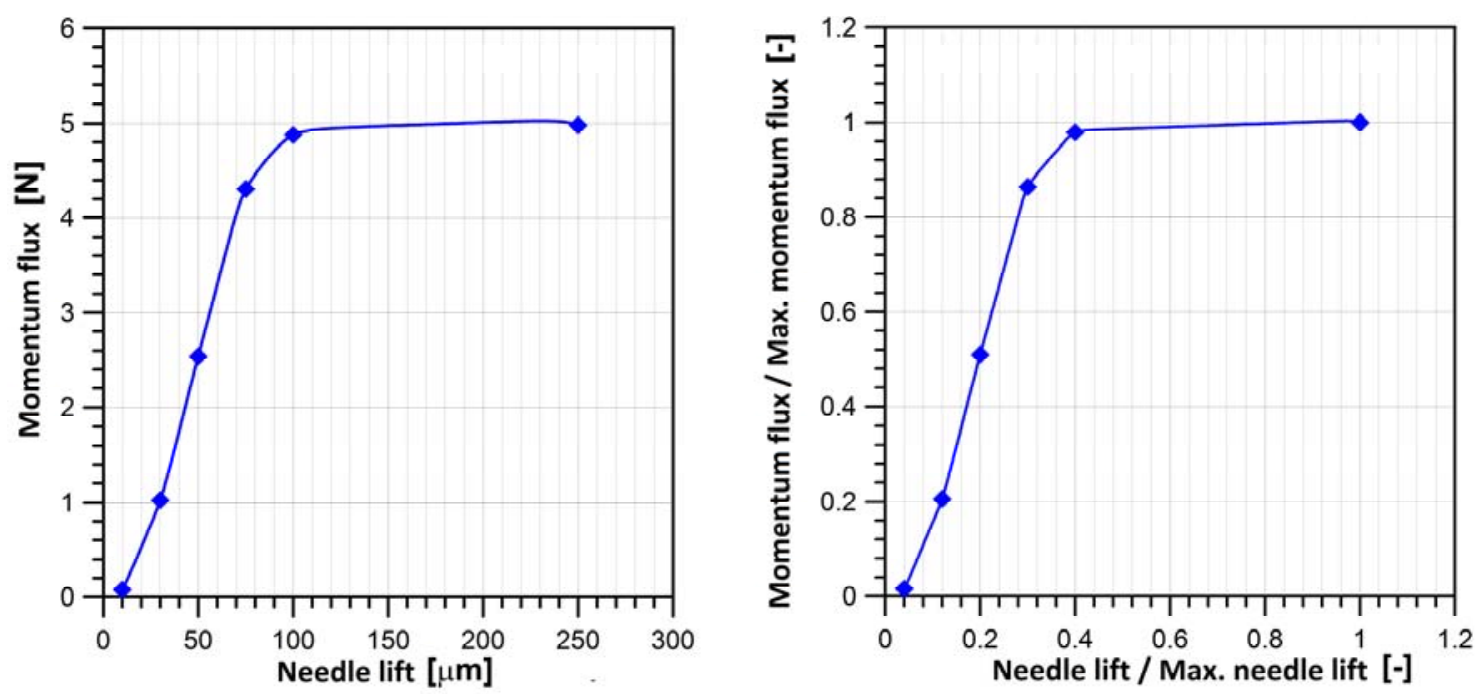

Figure 10. Momentum flux against needle lift: real values and dimensionless ones. 

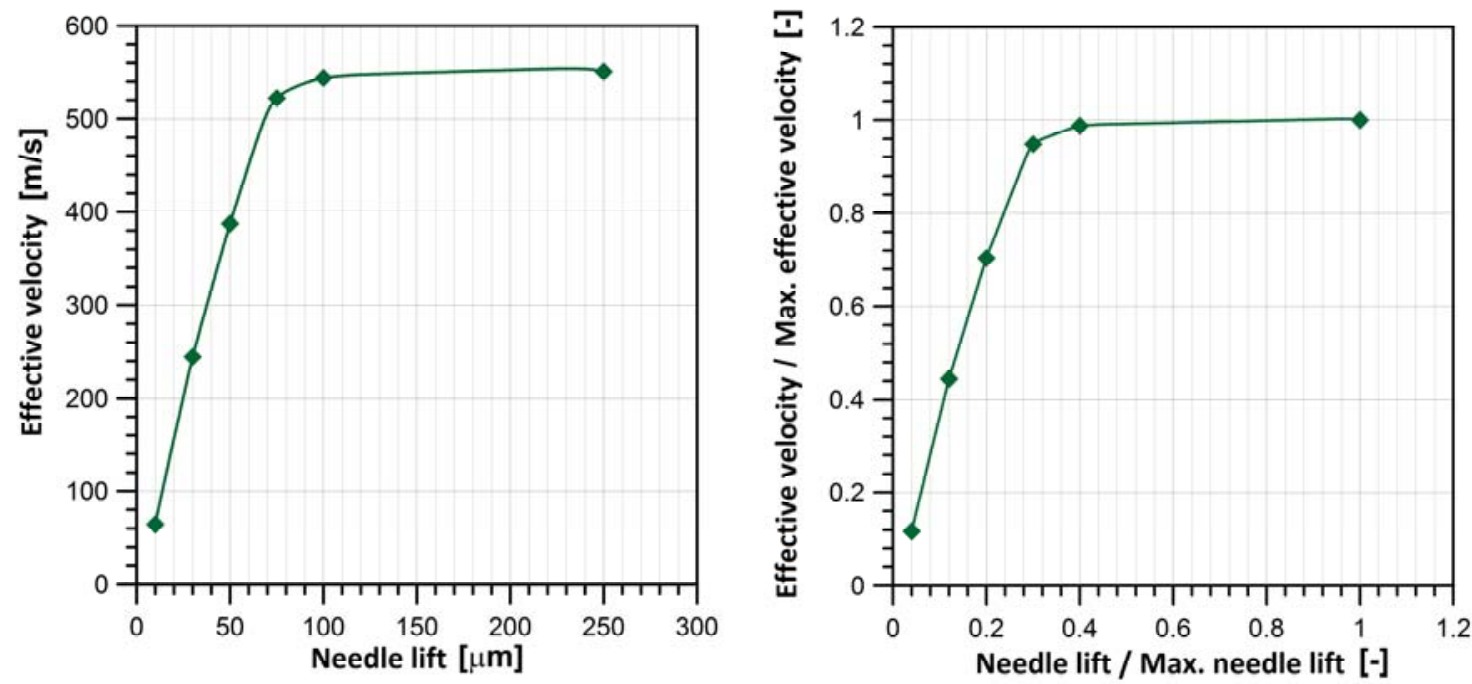

Figure 11. Effective velocity against needle lift: real values and dimensionless ones. 


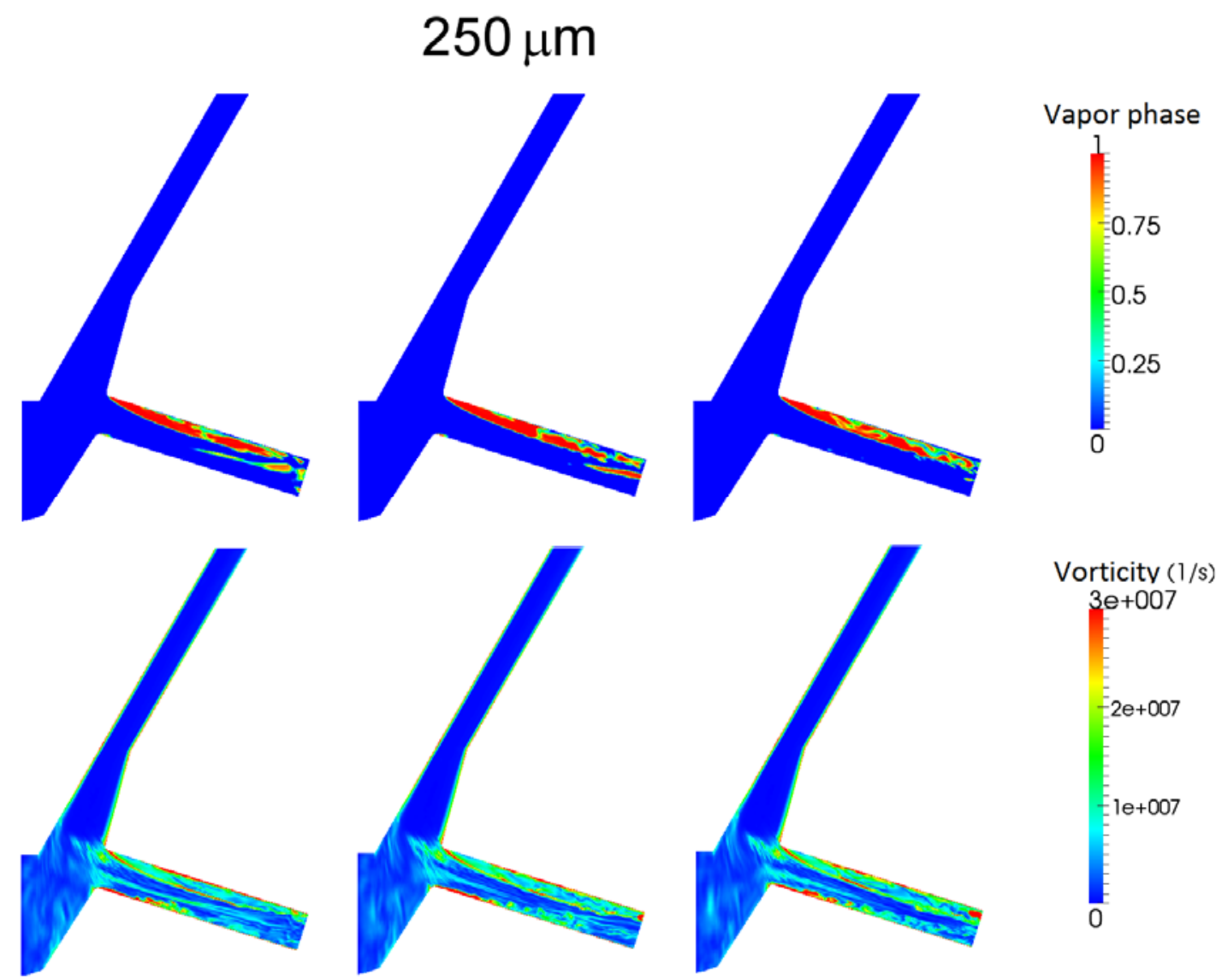

Figure 12. Vorticity and vapour phase field in the mean plane of the nozzle for three different time steps for a needle lift of $250 \mu \mathrm{m}$. 


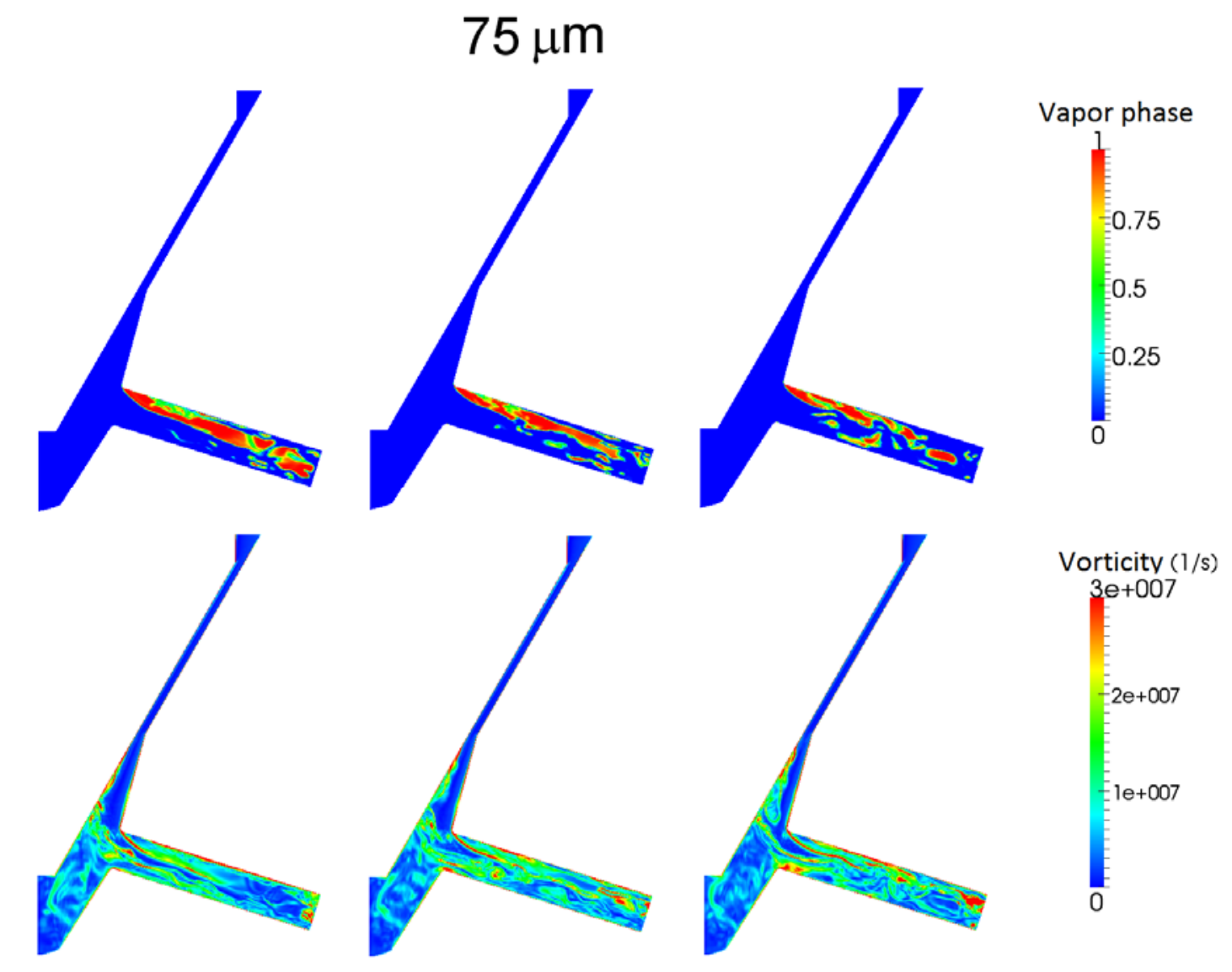

Figure 13. Vorticity and vapour phase field in the mean plane of the nozzle for three different time steps for a needle lift of $75 \mu \mathrm{m}$. 


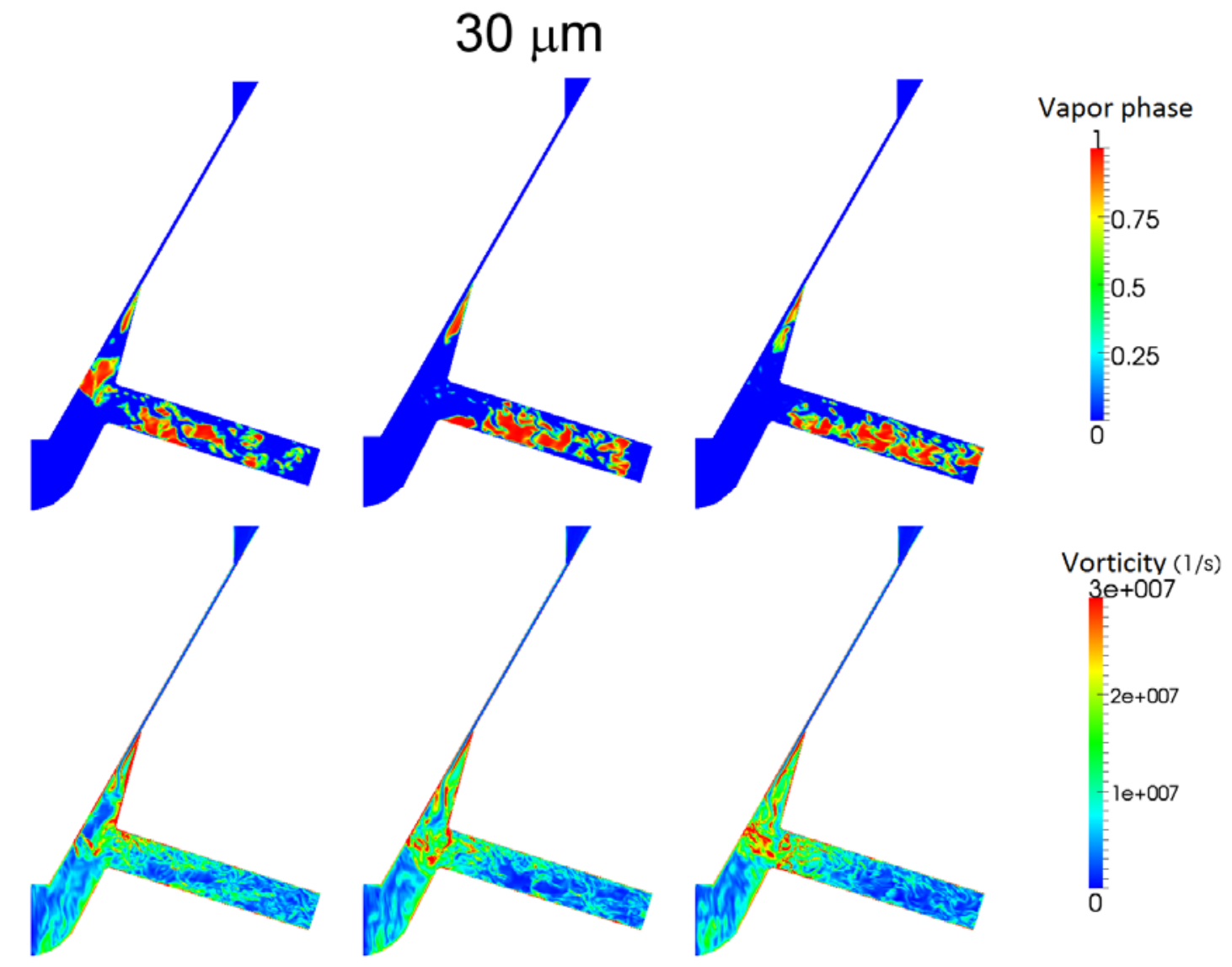

Figure 14. Vorticity and vapour phase field in the mean plane of the nozzle for three different time steps for a needle lift of $30 \mu \mathrm{m}$. 

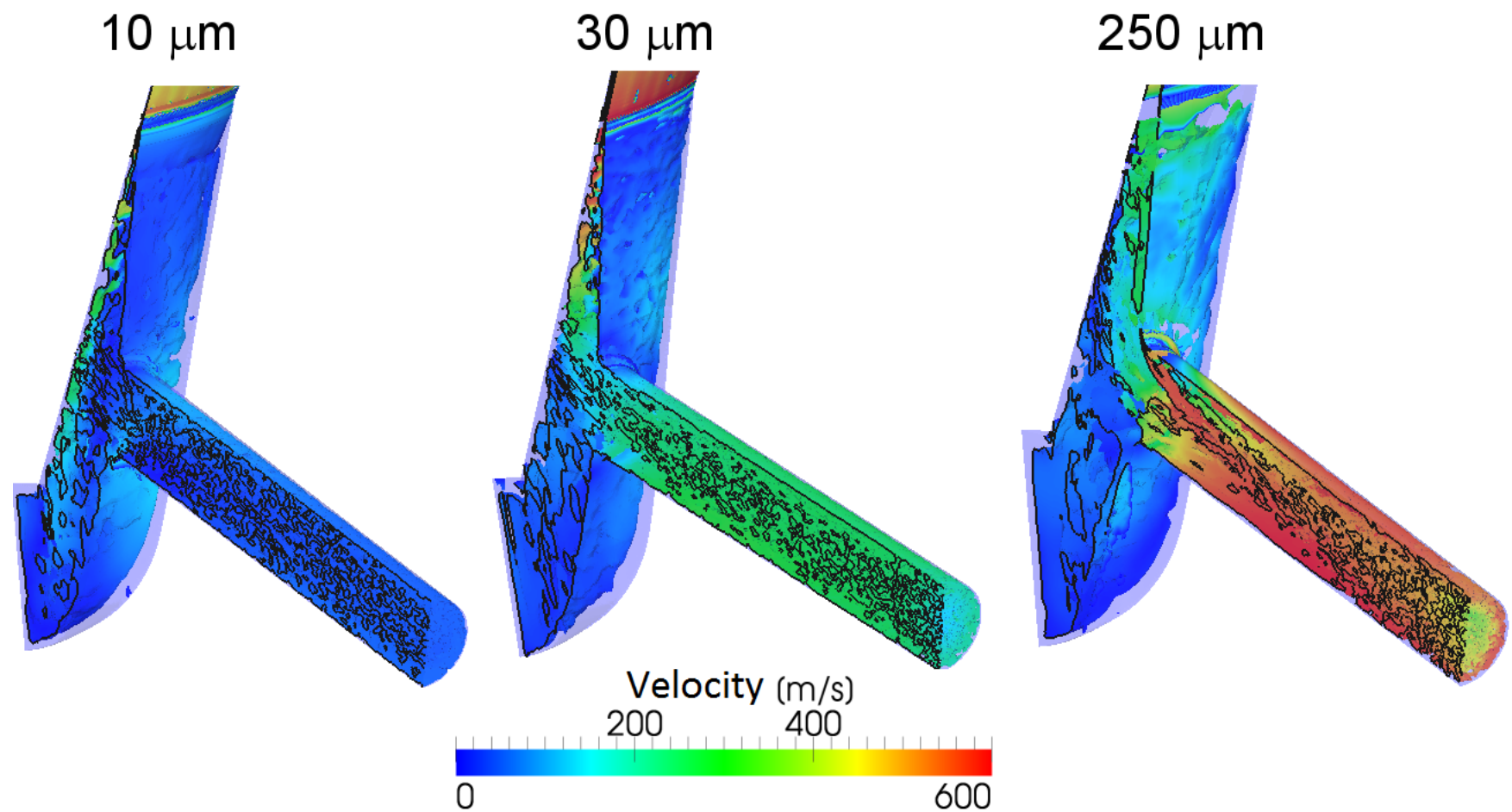

Figure 15 . Isosurfaces of $\mathrm{Q}>1.53 \cdot 10^{15} \mathrm{~s}^{-2}$ coloured by the velocity field. 


\section{NOTATION}

$a$ : speed of sound

$A^{+}$: constant to estimate the turbulent mixing length

Co: Courant number

Co acoustic: acoustic Courant number

Cs: constant used in the the Smagorinsky model

$D$ : diameter

$l$ : turbulent mixing length

$m:$ mass flow

$\dot{M}:$ momentum flux

$p$ : pressure

$P_{\text {back }}:$ backpressure

$P_{i n j}:$ injection pressure

$p_{\text {sat }}$ vaporization pressure

$Q$ : second invariant of the velocity

$S$ : rate-of-strain tensor

$t$ : time

$u$ : velocity

$u_{\text {eff: }}$ injection effective velocity

$\mathrm{y}$ : wall distance

$\mathrm{y}^{+}$: non dimensional wall-normal distance

\section{Greek symbols:}

$\Delta$ : local grid length scale

$\gamma$ : vapour fraction 
$\Delta \mathrm{P}$ : pressure drop, $\Delta P=P_{i n j}-P_{\text {back }}$

$\Delta t$ : time step

$\Delta x$ : cell length

$\mu$ : fluid viscosity

$\rho$ : fluid density

$\rho_{l \text { sat }}:$ liquid density at saturation

$\rho_{1}{ }^{0}$ : liquid density at a given temperature condition

$\rho_{v \text { sat }}:$ vapour density at saturation

$\tau$ : Sub-Grid Scale-Stress

$\Psi$ : fluid compressibility

$v$ : viscosity

$v_{t}:$ turbulent viscosity

$\omega$ : vorticity

\section{Subscripts:}

$l$ : liquid

$v$ : vapour 